Columbia Law School

Scholarship Archive

\title{
Marine-Salvage Law and Marine-Peril-Related Policy: A Second- Best and Third-Best Economic-Efficiency Analysis of the Problem, the Law, and the Classic Landes and Posner Study
}

Richard S. Markovits

rmarkovits@mail.law.utexas.edu

Follow this and additional works at: https://scholarship.law.columbia.edu/faculty_scholarship

Part of the Law and Economics Commons

\section{Recommended Citation}

Richard S. Markovits, Marine-Salvage Law and Marine-Peril-Related Policy: A Second-Best and Third-Best Economic-Efficiency Analysis of the Problem, the Law, and the Classic Landes and Posner Study, U of TeXAs LaW AND ECONOMics Research PAPER No. 43 (2005).

Available at: https://scholarship.law.columbia.edu/faculty_scholarship/1357

This Working Paper is brought to you for free and open access by the Faculty Publications at Scholarship Archive. It has been accepted for inclusion in Faculty Scholarship by an authorized administrator of Scholarship Archive. For more information, please contact scholarshiparchive@law.columbia.edu. 


\section{THE UNIVERSITY OF TEXAS SCHOOL OF LAW}

Law and Economics Working Paper No. 043

March 2005

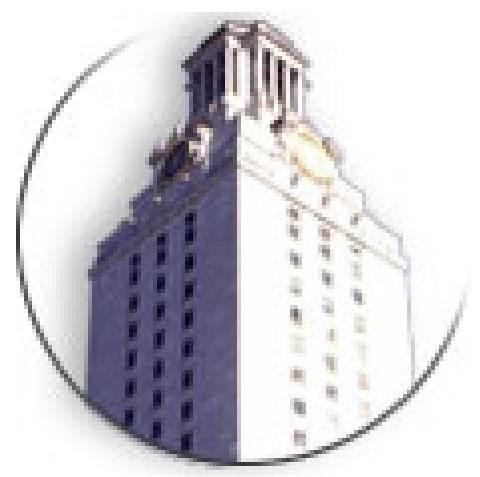

Marine-Salvage Law and Marine-Peril-Related Policy: A Second-Best and Third-Best Economic-Efficiency Analysis of the Problem, the Law, and the Classic Landes and Posner Study

Richard S. Markovits

The University of Texas School of Law

This paper can be downloaded without charge from the Social Science Research Network Electronic Paper Collection: http://ssrn.com/abstract $=680764$

An index to the working papers in

The University of Texas School of Law Working Paper Series

is located at http://www.utexas.edu/law/ 


\title{
MARINE-SALVAGE LAW AND MARINE-PERIL-RELATED POLICY: A SECOND-BEST AND THIRD- BEST ECONOMIC EFFICIENCY ANALYSIS OF THE PROBLEM, THE LAW, AND THE CLASSIC LANDES AND POSNER STUDY
}

\author{
(c) 2005 Richard S. Markovits
}

\begin{abstract}
This Article

(1) delineates the different kinds of allocative costs that marine-peril contingencies can generate and the different kinds of marine-peril-related decisions that can generate allocative inefficiency (marine-salvage-operation investment decisions; decisions about whether to offer to attempt or to actually attempt marine rescues; decisions about the character of the marine-rescue attempts that are made; decisions by potential rescuees to accept or reject offers of marine-rescue attempts; and decisions by potential rescuees to make or reject various marine-peril-avoidance moves);

(2) defines the formal meaning of "the most-allocatively-efficient response a State can make to marine-peril contingencies";

(3) explains why, standing alone, judge-prescribed marine-rescuee-to-rescuer-compensation awards cannot minimize the allocative cost that marine peril generates (the misallocation that marineperil-related decisions generate);
\end{abstract}

(4) discusses the interdependence of the various types of marine-peril-related decisions that can be made;

(5) defines the second-best-allocatively-efficient and the third-best-allocatively-efficient approach to deciding particular issues and the second-best-allocatively-efficient and third-best-allocativelyefficient resolution of a particular issue;

(6) executes a partial and preliminary second-best analysis of the factors that determine the impact of any marine-salvage-award formula both on each of the types of marine-peril-related misallocation such awards can affect and on the total amount of marine-peril-related misallocation that the use of any given marine-salvage-award formula will generate;

(7) speculates on the differences between the marine-salvor-compensation formula that is secondbest-allocatively-efficient and the formula that is third-best-allocatively-efficient;

(8) provides an account of the protocol the courts allegedly use to determine the compensation they order defendant marine rescuees to pay plaintiff marine rescuers who have not been able to negotiate a binding price for their services ;

(9) analyzes the second-best and third-best allocative efficiency of that protocol—i.e., delineates the respects in which that protocol is definitely not second-best-allocatively-efficient and explains why it is extraordinarily unlikely to be third-best-allocatively-efficient; 
(10) points out that the preceding analysis refutes Landes and Posner's claim that the law of marine salvage "is consistent with" and displays "impressive congruence with" their hypothesis that "the rules of judge-made law are best explained as efforts-however unwitting - to bring about [economically-]efficient results;"”

(11) delineates the structural deficiencies of the type of argument with which Landes and Posner attempt to establish their conclusion that marine-salvage law is allocatively efficient;

(12) asserts that Law \& Economics scholars who believe that "judge-made" law in general is allocatively efficient almost always attempt to justify this conclusion with the same type of argument that Landes and Posner made about marine-salvage law; and

(13) explains why it is important not only to refute the conclusion that "judge-made law" is allocatively efficient but to demonstrate the inadequacy of the type of argument with which scholars who believe that "judge-made law" is allocative efficient attempt to bolster this position. 


\title{
MARINE-SALVAGE LAW AND MARINE-PERIL-RELATED POLICY: A SECOND-BEST AND THIRD- BEST ECONOMIC-EFFICIENCY ANALYSIS OF THE PROBLEM, THE LAW, AND THE CLASSIC LANDES AND POSNER STUDY ${ }^{2}$
}

\author{
(C) 2005 Richard S. Markovits
}

This Article is concerned with the economic (henceforth allocative ${ }^{3}$ ) efficiency of various responses the State has made or could make to marine losses or marine-peril contingencies. More particularly, the Article (1) delineates two equivalent operationalizations of "the most-allocatively-efficient response a State could make to marine losses and marine-peril contingencies," (2) lists various types of policies that could be components of the most-allocatively-efficient response a State could make to such realities and possibilities, (3) describes the second-best-allocatively-efficient ${ }^{4}$ approach for a judicial system to take to suits in which successful salvos who have not been able to negotiate binding prices for their salvage services seek to obtain compensation from the owners of the salvage they rescued (and/or from other potential marine-peril victims whose losses they prevented), (4) speculates on the third-best-allocatively-efficient ${ }^{5}$ approach for a judicial system to take to such "marine-salvage" suits, (5) explains why a law granting such marine salvors a right to obtain compensation through a private law-suit that would be handled in such a third-best-allocatively-efficient way (A) would almost certainly not minimize the amount of misallocation generated by the marine-peril-related decisions of potential marine rescuers and potential marine rescuees, ${ }^{6}$ (B) would be unlikely to constitute the third-bestallocatively-efficient response the State could make to marine-peril contingencies, and (C) might be a component of such a third-best-allocatively-efficient response to marine-peril contingencies, (6) analyzes the various respects in which the courts' current approach to such marine-salvage cases (more accurately, the bestfitting account that can be given of judicial decisions that may in fact not be consistent) is not second-best or third-best allocatively efficient, (7) criticizes Landes and Posner’s claim that the common law of marine salvage

\footnotetext{
2 William A. Landes and Richard M. Posner, Salvors, Finders, Good Samaritans, and Other Rescuers (henceforth Landes and Posner), 7 J. LEG. IND. 83 (1978).

3 I substitute "allocative" for "economic" to remind readers that the concept of allocative efficiency is a technical economic concept and that choices that are allocatively efficient may be inconsistent with our rights-commitments and/or undesirable, rightsconsiderations aside. See Richard S. Markovits, On the Relevance of Economic Efficiency Conclusion, 29 FLA. ST. L. REV. 1 (2001). Admittedly, marine-salvage law is not concerned exclusively with marine peril in the sense of peril that arose at sea. Thus, the fact that goods flooded into the sea from the land and perhaps airplanes that crashed into the sea are salvageable shows that marine-salvage law may apply when a rescued object did not become imperiled at sea. However, for expositional reasons, the text will continue to use locutions that imply that marine-salvage law and policy are concerned with marine-peril issues_indeed, are concerned with situations that involve the imperilment of a ship on navigable waters.

$4 \quad$ The second-best-allocatively-efficient approach to any issue takes complete account of all Pareto imperfections present in the system that affect the allocative efficiency of the events or policy-options whose allocative efficiency is being analyzed.

5 Third-best-allocative-efficiency analysis takes account of the inevitable cost and inaccuracy of data and the inevitable cost and probable imperfectness of theoretical analysis when deciding what data to collect and what theoretical possibilities to consider. Third-best-allocative-efficiency analysis is the approach that is ex ante allocatively efficient, given the cost and imperfectness of data and analysis.

6 In marine-peril situations, the relevant "avoidance-choices” include not only the peril-avoiding choices of potential rescuees but also the loss-reducing choices of potential rescuers (who respectively stand in the shoes of potential victims and potential injurers in the conventional tort analysis).
} 
"is consistent with"7 and displays "impressive congruence with” their hypothesis that "the rules of judge-made law are best explained as efforts—-however unwitting — to bring about [economically-]efficient results,”8 and (8) criticizes the type of argument Landes and Posner use to support their claim.

The Article's analysis is important for at least five reasons. First, marine-salvage law is important in itself_-affects decisions that seem likely to have a considerable impact on allocative efficiency and do have a considerable distributive impact. ${ }^{9}$ Second, the full analysis of the allocative efficiency of marine-salvage law applies equally well not only to finders and Good Samaritan law (as Landes and Posner recognize) but also to tort law and environmental law (in multiple-care cases, in which allocative efficiency will be maximized only if both the potential injurer and the potential victim engage in appropriate avoidance). Third, half of the analysis of the allocative efficiency of marine-salvage law (the part that focuses on the potential rescuer) applies to individual-care ${ }^{10}$ tort and environmental situations and to intellectual-property problems (in which the potential discoverer or information-disseminator occupies the position of the potential rescuer or potential injurer). Fourth, the Article's analysis of the allocative efficiency of marine-salvage law takes account of generalequilibrium feedback-loops and The General Theory of Second Best ${ }^{11}$ — two considerations that are virtually always critical and that virtually all Law \& Economics scholarship ignores. And fifth, this Article is important

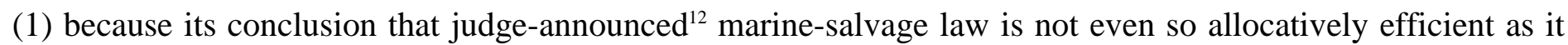

\footnotetext{
$7 \quad$ See Landes and Posner at 102.

$8 \quad$ Id. at 128.
}

9 See, e.g., Brough's account of the dollar amounts involved in the salvage cases heard by the American Institute of Marine Underwriters in Wayne T. Brough, Liability Salvage-by Private Ordering (henceforth Brough), 19 J. LEG. STUD. 95 , 109 n. 40 (1990).

10 In my terminology, "individual-care" situations are situations in which the most-allocatively-efficient response to an accident-or-pollution-loss contingency is for either the potential victim or the potential injurer to avoid. Such situations are contrasted with "no-care" and "multiple-care" situations, in which the most-allocatively-efficient response to such a contingency is respectively for no-one to avoid and for both the potential victim and the potential injurer to engage in some avoidance. I substitute the expression "multiple-care" for its standard counterpart "joint-care" to avoid giving the impression that, in multiple-care situations, the potential victim and potential injurer must arrange the coordination of their avoidance-moves-e.g., by discussing their responses. I should point out that, in my usage, joint-care situations are not synonymous with situations in which "joint torts" may occur-i.e., with situations in which any resulting loss will have been caused by the choices of multiple potential injurers (by more than one "joint tortfeasor”).

11 General-equilibrium analysis takes account of the interrelationship between various decisions-for example, a generalequilibrium analysis of the impact of some choice on outcomes in one "sector" of the economy will take account of the way in which the choice in question will influence outcomes in that sector indirectly by influencing choices made in other sectors of the economy. The General Theory of Second Best asserts the following proposition: Given a series of conditions whose fulfillment guarantees the attainment of an optimum, if one or more of these conditions cannot be fulfilled, there is no general reason to believe that fulfilling or more closely approximating more of the remaining conditions will bring one closer to the optimum than fulfilling or more closely approximating fewer of the remaining conditions. The intuitive justification for this proposition focuses on the fact that the "imperfections" one can remove will in general be as likely to counteract as to compound the "imperfections" one cannot or will not eliminate. Virtually all Law \& Economics economic-efficiency analyses ignore The General Theory of Second Best-proceed on the assumption that any policy that reduces the number or extent of Pareto imperfections in the economy (that reduces the extent to which the conditions for maximum allocative efficiency are not fulfilled) will on that account increase allocative efficiency. For the first formal statement of this General Theory, see Kelvin Lancaster and Richard Lipsey, The General Theory of the Second Best, 24 REV. ECON. STUD. 11 (1956). For a more general discussion of the significance of Second-Best Theory for legal scholarship, see Richard S. Markovits, Second-Best Theory and Law \& Economics, 73 CHI.-KeNT L. REV. 3 (1998).

12 I use the expression "judge-announced" law to avoid the following issue: Do judges find the law or make new law in cases in which the internally-right answer to the legal-rights issue posed is contestable? My own clearly-contestable position is that judges find the law in all such cases. For an explanation, see RichARD S. MARKOVITS, MATTERS OF PRINCIPLE: LEGITIMATE LEGAL ARgumEnT AND CONSTITUTIONAL InTERPRETATION (1998). Virtually all Law \& Economics scholars believe that judges make the 
could be runs counter not only to Landes and Posner's conclusion to the contrary but to a more general (equally-wrong) “Chicago” claim that all judge-announced law is in some (ill-specified) sense economically efficient and (2) because its argument reveals the deficiencies of the type of argument that Landes and Posner and others use to support their “economic efficiency of judge-made law” claim.

1. The Notion of the Most-Allocatively-Efficient Response for the State to Make to Marine-Peril Contingencies_-Two Equivalent Operationalizations

This section delineates two equivalent and somewhat overlapping operationalizations of the notion "the most-allocatively-efficient response the State could make to marine-peril contingencies.” The first defines that response to be "the response that minimizes the allocative costs the relevant possible perils will generate" and then proceeds to list the various categories of costs in question. The second defines that response to be "the response that causes no allocative inefficiency" or (somewhat more accurately) "the response that minimizes the sum of the allocative inefficiency generated by non-governmental marine-peril-related decisions, the allocative transaction cost of creating and implementing marine-peril-related public policies, the other sorts of allocative costs that related public-financing decisions generate, the allocative transaction costs that private parties generate when entering into marine-peril-related contracts (say, insurance, rescue, and post-loss salvage contracts), the allocative risk costs that are the allocative counterparts of the marine-peril-related risk costs that various private actors bear, and the distributive-value-related and distributive-preference-related equivalentdollar losses generated by the distributive impact of marine peril and marine-peril-related public policies and then proceeds to list the various "types" of private-decision-generated allocative inefficiency, public-policy creation-and-implementation allocative transaction costs, other sorts of public-policy-financing allocative costs, and private party-generated allocative transaction costs that possible responses could cause.

More specifically, it is useful to distinguish ten types of allocative costs that marine losses or marineperil contingencies can generate:

(1) the fixed allocative cost of marine-salvage operations ${ }^{13}$ (net of any allocative gains that speciallyconstructed [specially-adapted] salvage ships generate when performing non-salvage services [that they could not otherwise have supplied] such as towing) - the allocative cost of building marine-salvage ships, of adapting passenger and cargo ships to make them more cost/effective marine salvors, of hiring officers and crew members to supply marine-salvage services, of training such personnel to supply such services, and of placing ships in positions that increase their marine-rescue productivity;

(2) the variable non-environmental allocative cost of rescue-attempts-allocative fuel costs, the allocative cost of wearing out marine-rescue ships and equipment, the allocative cost that is generated when marine-rescue ships and equipment are damaged or lost, the allocative cost that is generated when marine-rescue personnel are injured or killed, the allocative cost that is

\footnotetext{
law in such cases. See, e.g., the Landes and Posner reference to "judge-made law" in the quote included in the text prior to note 7 supra.

13 For example, according to Wayne Brough: "Salvage tugs are equipped with chain (4,500 feet), excess electrical power, towing winches, air compressors, cranes, and many other pieces of equipment unique to rescue operations."
} 
generated when passenger and cargo on semi-professional or casual salvaging ships are injured/killed or damaged/lost, the allocative cost of delaying the arrival of passengers and cargo at their destination, and the allocative opportunity cost generated when the salvaging ship's rescue-efforts require it to forego other opportunities;

(3) the variable environmental allocative cost of rescue-attempts-generated, for example, when a salvor releases some of the oil a tanker is carrying to lighten the ship to facilitate its rescue;

(4) the allocative cost of lost or damaged salvage-i.e., of lost or damaged ships, of lost or damaged cargo, and of passenger, crew, and officer injuries and deaths;

(5) the environmental allocative costs marine accidents generate that can not be attributed to salvor efforts-i.e., that are caused by oil spills, leaks of other toxic materials, shipping-lane blockages, or the rusting of sunken ships that salvor-efforts did not actively cause but also did not prevent;

(6) the allocative cost of potential-rescuee avoidance-moves - the allocative cost or allocative loss (salvage-losses aside) that are generated by decisions not to purchase passenger or cargo ships, to buy ships with thicker hulls, to keep on board spare parts (such as propellers and engine components), to hire more and better-trained mechanics, to give officers and crew more safetytraining, to pack cargo in water-resistant or flame-resistant containers, to stow cargo in safer positions, to reduce the physical volume, value, vulnerability, or dangerousness of the cargo carried, to reduce the number, vulnerability, and wealth (life-value) of the passengers transported, to reduce the number of trips each ship operated makes in any given time-period, to travel by more circuitous but safer routes, to travel at safer times of the year, to travel under safer weather conditions, ${ }^{14}$ etc.;

(7) the marine-peril-related risk costs that marine salvors and potential victims of marine peril bear;

(8) the allocative transaction costs generated by (A) the marine-peril-related policies the government adopts, ${ }^{15}$ (B) the consideration, formation, and enforcement of marine-peril-related insurance contracts, and (C) the consideration, formulation, and enforcement of any marine-salvage contracts relevant parties contemplate entering into or actually enter into;

(9) the allocative cost of any choices the government made to finance its marine-peril-related policies - the sum of the allocative transaction cost of devising and collecting any additional taxes that are levied, the non-transaction-cost-related misallocation any such taxes generated, and the misallocation caused by the elimination of other expenditures the State forewent to finance its marine-peril-related policies; and

(10) any income-distribution-preference-related net external costs (or net external benefits) generated by the relevant marine perils and government policies.

In any event, according to the first operationalization of the concept of "the most-allocatively-efficient response a State could make to marine-peril contingencies,” that response would be one that minimized the sum of the above ten allocative costs.

14 Some of the items in this list are taken from Note, Calculating and Allocating Salvage Liability (henceforth HARVARD Note), 99 HARV. L. REV. 1896, 1902 n. 26 (1986).

See Section 2 for a list of the marine-peril-related policies a State could adopt. 
I have already listed the various kinds of non-public-finance-related government-generated allocative transaction costs, privately-generated allocative transaction costs, allocative risk costs, and distributive-valueor-preference-related allocative costs that can occur when particular policies are adopted. Those costs will also appear in the second, misallocation-oriented concretization of "the most-allocatively-efficient response the State can make to marine peril." In addition, that concretization would list the following four "types" of misallocation that private marine-peril-related decisions could generate or fail to eliminate:

(1) the amount of misallocation caused by the fixed-cost choices of potential marine rescuers (choices about constructing salvage ships, adapting non-salvage ships, hiring and training officers and crew, and deploying ships that could effectuate marine rescues) that the policy or policy-package generates or fails to eliminate;

(2) the amount of misallocation caused by the variable-cost choices of potential rescuers (choices about rescue-attempts - about whether to attempt given rescues and the characteristics of any rescue-attempt that is made) that the policy or policy-package generates or fails to eliminate;

(3) the amount of misallocation caused by the various avoidance-choices made by potential marine rescuees-delineated in item (6) of the preceding list-that the policy or policy-package generates or fails to eliminate; and

(4) the misallocation generated by decisions of owners of imperiled ships to reject or accept offers of rescue-assistance.

In any event, on this second operationalization, the most-allocatively-efficient response to marine-peril-related contingencies is the response that minimizes the sum of the allocative costs I began this paragraph by listing and the amounts of misallocation of each type just distinguished.

Before proceeding, I want to correct a misleading impression that the two lists I have just delineated might create. More specifically, the lists may suggest that each type of marine-peril-related choice that can be made and the allocative costs and misallocation each of these types of choices will generate can be analyzed separately. In fact, that is not the case. Fixed-cost-of-marine-salvage-operation decisions, variable-cost-ofrescue-attempt decisions, potential-rescuee marine-peril-avoidance decisions, and potential-rescuee decisions about whether to accept rescue-attempt offers are all interdependent, and the compensation that courts require marine rescuees to pay rescuers who have not been able to negotiate binding prices for their services affect each of these types of decisions as well as the allocative costs and misallocation they generate not only directly but also indirectly by affecting the other types of marine-peril-related decisions with which each of these types of decisions is interdependent. Obviously, the interdependence of these decisions and hence of the effects they generate will complicate the second-best and third-best analysis of the allocative efficiency of marine-salvage awards and marine-peril-related policy regardless of whether that analysis focuses on the total allocative costs that marine peril generates or the sum of (1) the marine-peril-related misallocation that private decisions generate, (2) the allocative transaction costs that the government's marine-peril-related policies generate, (3) the other allocative costs that the financing of those policies generates, (4) the allocative transaction costs that 
parties generate when responding to marine peril, (5) the allocative risk costs that are the allocative counterparts to the private risk costs that marine peril imposes on private actors, and (6) distributive-preference/value-related marine-peril-related costs.

The second-best and third-best allocative-efficiency analyses that this Article executes focus on the second of the two preceding operationalizations of the concepts "the most-allocatively-efficient compensationawards a judicial system could make" and "the most-allocatively-efficient response a State could make to marine-peril contingencies." I find it more convenient to focus on misallocation than on allocative costs (to the extent that this distinction matters) because, as a welfare economist, I am trained to analyze the circumstances in which resources will be misallocated in various ways.

2. The Possible Components of the Most-Allocatively-Efficient Response a State Can Make to MarinePeril Contingencies

A wide variety of policies might be components of the most-allocatively-efficient State response to marine-peril-related contingencies:

(1) government choices to supply rescue-services itself;

(2) government policies about the pricing or other financing of such government-supplied rescueservices;

(3) government subsidies paid to or taxes levied on private professional marine salvors;

(4) government regulations of the attributes of salvage boats and the qualifications and training of their owners, captains, and crews;

(5) government licensing schemes for marine salvors (that determine both the number and attributes of professional and semi-professional salvors);

(6) government regulations about the geographic disposition of salvage boats;

(7) government imposition of a legal duty to rescue on potential salvors in specified situations;

(8) government regulations controlling which potential salvor(s) may attempt a rescue when more than one potential rescuer is in position to make such an attempt-regulations backed up by civil fines and/or the possibility of license-cancellations;

(9) government regulations of the priorities that should guide any rescue-attempt that is made and/or of the methods a salvor may or must employ when attempting a rescue-regulations backed up by civil fines and/or the possibility of license-cancellations;

(10) government-financial compensation-schemes for those who have attempted to perform a marine rescue or have succeeded in such an attempt (schemes that may make the salvor's award depend either exclusively or inter alia on whether the salvor was supposed to attempt the rescue, on whether he made his attempt with a ship that departed from a government-approved location, and on whether his attempt used the recommended techniques); 
(11) government-finance schemes that finance awards to those who have attempted marine rescues from taxes or fees levied on those who ship goods over the seas, who travel on the seas, and/or who provide marine-transport services;

(12) government decisions to impose fines on any salvor whose rescue-efforts generated environmental damage (e.g., who released oil from an imperiled ship to facilitate its rescue) or to establish a private-law right of those who have been harmed by any oil spill or other hazardoussubstance spill that the salvor caused to recover those losses from the salvor (perhaps combined with a policy of requiring all salvors to insure against this contingency);

(13) government policies (license schemes or tax or subsidy policies) designed to control the number of passenger ships and/or freighters in operation;

(14) government regulations of the attributes of ships that travel the seas (for example, of the thickness of the hulls of ships that carry certain types of cargo or travel certain routes);

(15) government regulations backed up by civil fines and/or the possibility of a license-cancellation of the types of cargo that may be shipped;

(16) similarly enforced government regulations of the way in which cargo of different types must be stowed;

(17) similarly enforced government regulations of the safety training of ship officers and crew;

(18) similarly enforced government regulations of the routes ships may take, the times of the year they may operate on certain routes, and/or the weather conditions under which they may operate (with certain cargo, at certain times of the year, along certain routes?);

(19) government choices to pay compensation to salvors who have made (appropriate) rescueattempts or have succeeded in rescuing ships, cargo, and/or lives or in preventing environmental damage;

(20) government decisions to confer a legal right on those who have attempted a marine rescue or have succeeded in rescuing ships, cargo, and lives or preventing spills that would have damaged the environment to obtain compensation from the beneficiaries of their salvage activitiescompensation that might be made to vary with the fixed cost of the salvor, the variable cost of the salvage attempt, the weighted-average-expected benefits of the rescue-attempt, and/or many other factors; and

(21) various other policies the government could devise to alter the distributive consequences of marine-peril-related contingencies (and various decisions that might otherwise cause allocative inefficiency that could be affected by marine-peril risks) — various government-transfer-toindividuals programs (medicare, welfare, disability, unemployment-insurance, widow's benefits policies), corporate-bailout programs, and individual and business bankruptcy policies.

3. The Approach That Would be Second-Best-Allocatively-Efficient for a Judicial System to Take to Marine-Rescuee-to-Rescuer Compensation-Award Cases

If a judicial system could execute all relevant theoretical analyses perfectly and costlessly and could estimate all the parameters those analyses deemed relevant perfectly and costlessly, how should it determine the 
compensation that the beneficiaries of marine rescues should be required to pay their salvors ${ }^{16}$ if the goal is to maximize allocative efficiency? Unfortunately, one would need to write a book-length manuscript to delineate and explain the approach that would be second-best-allocatively-efficient ${ }^{17}$ for a judicial system to take to such compensation issues. In part, the complexity of the second-best-allocative-efficiency approach to setting such marine-salvor-compensation awards reflects the fact that the set of awards that are made will affect allocative efficiency in several different ways-for example, by influencing (1) the number of professional, semiprofessional, and casual salvors ${ }^{18}$ - inter alia, the number of salvage ships that are constructed, the frequency with which and extent to which ships not primarily designed to engage in salvage operations are altered or equipped to increase their ability to provide rescue services, and the frequency with which and extent to which the hiring and training of the personnel of such semi-professional salvage-ships is altered to increase their ability to perform salvage services, (2) the number and character of the rescue-attempts made on each imperiled ship_-inter alia, the number of rescue-offers made on each imperiled ship, the percentage of such offers that are accepted, the number of rescue-attempts made in circumstances in which the rescuee could not receive or accept a rescue-attempt offer, and (3) the amount and character of the avoidance in which potential rescues engage. In part, it reflects the fact that the compensation that marine rescuees are required to pay marine salvors will affect each of the above factors not only directly but also indirectly since the associated decisions are interactiveindeed, are simultaneously interactive. ${ }^{19}$ In part, it reflects the complexity of the task of identifying the set of rescue-attempts on any given imperiled ship that would be most allocatively efficient, given the number of salvage ships constructed and their geographic disposition (a complexity that reflects inter alia the following facts - the fact that in situations in which more than one rescue-attempt is being made each attempt that is made

16 This way of posing the issue assumes that only successful rescuers will be able to secure compensation from the potential beneficiaries of their rescue-attempts. Although this is a feature of our current law and Landes and Posner have attempted to argue for its allocative efficiency, a system that entitles unsuccessful as well as successful rescue-attempters to obtain compensation from their efforts' potential beneficiaries might in fact be more allocatively efficient. See Landes and Posner at 104. This Article analyzes this possibility in the text of Section 6 in the paragraph that contains note 45.

$17 \quad$ For such a detailed account, see Richard S. Markovits, Marine Salvage Policy and the Law of Marine Salvage: A First-Best, Second-Best, and Third-Best Allocative-Efficiency Analysis (unpublished book manuscript. 2005).

18 In my terminology, "professional marine salvors" operate ships that are specially designed to effectuate marine rescues with personnel that have been primarily selected and trained to perform marine rescues. "Semi-professional marine salvors" operate ships that have been primarily designed to perform other functions but have been altered or equipped to some extent to perform marine rescues with personnel who were primarily selected and trained to perform other functions but may also have been selected and trained to some extent to perform marine rescues. "Casual marine salvor" operate ships whose construction and equipment have not been influenced at all by the possibility of their attempting marine rescues and use personnel whose selection and training was not at all affected by this possibility.

19 Thus, although the direct impact of increases in individual salvage awards on the number of salvage ships that are built will be positive, the indirect impact of such salvage-award changes cannot be predicted on a priori grounds. In the one direction, higher individual awards will tend to have an indirect negative impact on the profits a salvage ship can earn (1) by decreasing the number of rescue-opportunities any given salvor will have (A) by increasing the amount of avoidance in which potential rescuees engage by increasing the cost to them of any rescue-services for which they must pay and (B) by increasing the percentage of rescue-offers that potential rescuees reject and (2) by increasing the number of rescue-attempts that will be made on any given imperiled ship that accepts offers of help or is not in a position to reject rescue-service offers, controlling for the number of salvage ships in operation. In the other direction, higher individual awards will tend to have an indirect positive impact on the profits a salvage ship can earn by increasing the number of rescue-opportunities any given salvor will have by reducing the amount of avoidance in which potential rescuees engage by reducing the probability that their ship, cargo, officers, crew, and passengers will be lost if they become imperiled by increasing the probability that one or more rescue-attempts will be made on them if they are imperiled. 
will affect the allocative benefits the other attempts should be expected on the weighted average to generate, the

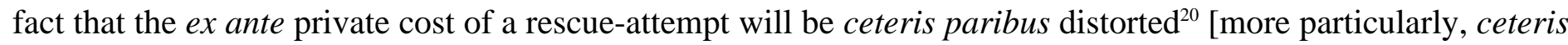
paribus deflated $^{21}$ ] to the extent it increases the weighted-average environmental loss the relevant contingency should be expected to generate [if the rescue-attempter might not be liable for the relevant environmental loss or, in practice, might not have to compensate the relevant environmental victims], the fact that the ex ante private benefits of a rescue-attempt will be ceteris paribus deflated to the extent that it would reduce the size of the environmental loss that one should expect on the weighted average to be generated [if the salvor might not be legally entitled to obtain compensation from or, in practice, might not be able to secure compensation from his environmental beneficiaries], and the fact that various imperfections in competition [as well as other sorts of Pareto imperfections] will on their own distort the private cost, the private benefits, and derivatively the private profitability of given rescue-attempts ${ }^{22}$ ). In part, it reflects the complexity of the task of identifying the set of salvage-ship-construction decisions that would be most allocatively efficient if the resulting most-allocativelyefficient set of salvage ships would be used as allocatively efficiently as they could be used (a complexity that reflects inter alia the difficulty of determining the set of geographical-disposition decisions and rescue-attempt decisions that would be most allocatively efficient [given the creation of the most-allocatively-efficient set of salvage ships], the difficulty of identifying the impact of the creation and operation of this set of salvage ships on potential-rescuee avoidance-decisions [given the "formula" the courts were using to determine the salvageawards marine rescuees are legally obligated to pay their rescuers], the complications introduced by the fact that various Pareto imperfections will distort both the private cost of constructing salvage ships and the private profits such ships will generate when performing functions for compensation not directly determined by marinesalvage law [e.g., when supplying towing services or raising sunken ships and cargo for a price determined by contract, etc.]) or, more to the point, the complexity of the task of identifying the set of salvage-shipconstruction decisions that would be most allocatively efficient, given the way in which any ships that would be constructed would actually be used (which will be affected both directly and indirectly by the marine-salvagecompensation awards that determine the set of salvage-ship-construction decisions that are made). In part, it reflects the substantial differences among the marine-salvage-compensation awards that will respectively induce (1) potential rescuees to make allocatively-efficient avoidance-decisions and rescue-attempt-offer acceptance/rejection decisions, (2) potential salvors to make allocatively-efficient salvage-ship-construction and deployment decisions, and (3) potential salvors who are in a position to make a rescue-attempt to make

20 In my terminology, a private cost, benefit, or profit figure is "distorted" to the extent that it diverges from its allocative counterpart. Relatedly, a private cost, benefit, or profit figure is said to be ceteris paribus distorted by some Pareto imperfection if that imperfection would distort the private figure in question in an otherwise-Pareto-perfect world ("if other things were equal").

21 In my terminology, a private figure is said to be "deflated" to the extent that it is lower than its allocative counterpart. Relatedly, a private figure is said to be "inflated" to the extent that it is higher than its allocative counterpart.

${ }_{22} \quad$ For an explanation, see Richard S. Markovits, On the Economic Efficiency of Using Law to Increase Research and Development: A Critique of Various Tax, Antitrust, Intellectual Property, and Tort Law Rules and Policy Proposals, 39 HARV. J. ON LEG. 63, 78-101 (2002) and Monopoly and the Allocative Inefficiency of First-Best-Allocatively-Efficient Tort Law in Our WorseThan-Second-Best World: The Whys and Some Therefores, 46 CASE W. RES. L. REV. 313, 347-64 (1996). 
allocatively-efficient rescue-attempt decisions of various types-a reality that reflects inter alia the difference between the marginal cost of making a marine-rescue attempt and the average total cost of such attempts. And finally, in part, it reflects the complexity of determining the impact of using different compensation-award formulae on (1) the amount of misallocation that potential rescuees generate when making avoidance-decisions and acceptance-of-rescue-offer decisions, (2) the amount of misallocation that potential salvors generate when making salvage-ship-construction decisions, salvage-ship-deployment decisions, and various types of rescueattempt decisions, and (3) the total misallocation that all the above decisions generate.

3. The Second-Best-Allocatively-Efficient Approach for Courts to Take to Determining the Compensation That the Beneficiaries of Marine Rescues Are Required to Pay Those of Their "Rescuers" Who Have Not Been Able to Negotiate Binding Prices for Their Services

As I have already noted, ${ }^{23}$ second-best-allocative-efficiency (SBLE) analysis proceeds on the assumption that the analyst can execute all relevant theoretical analyses perfectly and costlessly and can collect perfect data on all parameters that such theoretical analyses reveal to be relevant without generating any allocative costs. This section examines the approach that would be second-best-allocatively-efficient (also SBLE) for courts or anyone else to take to determining the compensation that courts should require marine-rescue beneficiaries to pay their rescuers when the parties have not negotiated a binding price for the rescue-service. As Section 1's discussion of the two possible operationalizations of the notion "the most-allocatively-efficient response a State could make to marine-peril contingencies” suggests, this SBLE approach could be oriented either toward the various types of allocative costs that marine peril can generate or toward the various types of misallocation that such judicially-mandated compensation-awards can generate. In either eventuality, the relevant approach would begin by listing the various formulae that courts could use to calculate the award they would make in any marine-rescue case and determining the award that would be made in each case that might be brought if a particular formula were used. At this point, the two approaches to picking the most-allocatively-efficient award-formula a court could use in these cases would diverge.

If the "marine-peril-related allocative cost"-oriented approach is used, the analyst would proceed by examining the impact of each possible award-formula on the following sets of decisions:

(1) potential-rescuee avoidance-decisions;

(2) salvage-ship construction and non-salvage-ship-adaptation decisions;

(3) salvor-personnel hiring and training decisions;

(4) professional and semi-professional salvage-ship deployment-decisions; and

(5) rescue-attempt offer, acceptance, and execution decisions. 
The analyst would then calculate the total allocative cost that marine peril would generate if each possible compensation-award formula were used-i.e., if the just-listed decisions that would be induced by the use of each such formula were made-and identify the formula whose use would minimize the total allocative cost in question (and, if the analyst is the highest court in the relevant jurisdiction, require all courts to use the formula in question to resolve marine-salvor-compensation cases). Before proceeding to outline the second, misallocation-oriented SBLE approach to determining the formula in question, I want to emphasize something that my previous comment about the interdependence of many of the decisions just listed should have made obvious: the analysis I have just described will be extremely complicated (a fact that has no bearing on the substance of the approach that would be SBLE but will affect the approach that would be third-bestallocatively-efficient ${ }^{24}$ [TBLE] for the highest court of some jurisdiction or any other analyst of this issue to adopt).

If the "misallocation caused by the selected award-formula"-oriented approach is used, the analyst would proceed by examining the impact of each award-formula that might be used on the following six types of misallocation:

(1) the misallocation that is generated because offers to make ex ante allocatively-efficient rescueattempts are rejected;

(2) the misallocation that is generated because-given the resources allocated to the attempts to rescue particular imperiled ships and their cargo, passengers, and personnel (and/or to prevent any environmental damage that might result)—allocative efficiency would have been increased had a different individual rescue-attempt or a different set of rescue-attempts been made on one or more imperiled ships (because the alternative rescue-attempt or set of rescue-attempts would have generated greater allocative benefits);

(3) the misallocation that is generated because the number of rescue-attempts made on particular imperiled ships is allocatively inefficient, given the number of professional, semi-professional, and casual salvors in operation and their deployment;

(4) the misallocation that is generated by the various fixed-cost decisions of potential salvorsdecisions about the amount of money to spend on constructing salvage ships, adapting ships not specially built to perform marine rescues, hiring and training personnel to make them better able to effectuate rescues; decisions about the specific things that that money is spent on (the attributes of the salvage-ships that are built, the attributes of the adaptations that are made in other ships, the characteristics of and training given to personnel that will be used in salvage operations); decisions about the deployment of the salvage ships that have been built and of the other ships that have been adapted to make them more cost-effective salvors; and

(5) the misallocation that is generated by potential-rescuee avoidance-decisions.

Once more, in part because many of these sets of decisions are interdependent and, relatedly, because the attempt to analyze separately the misallocation that each such type of decision will generate is problematic if not misguided, the required analysis will be very complicated. However, despite all the attendant difficulties, 
my suspicion is that the TBLE approach for a court to use to identify the most-allocatively-efficient marinesalvage-award formula a judicial system could employ will be “misallocation caused by government decision”oriented rather than "allocative costs generated by marine peril”-oriented. I will therefore give more attention to the five calculations associated with the former approach than I gave to their counterparts for the latter approach.

I begin with the effect of marine-salvor-compensation awards on the misallocation that potential rescuees generate by accepting or rejecting offers of marine-rescue services. Sovereign, maximizing potential rescuees will reject an offer of allocatively-efficient rescue-services only if the certainty-equivalent private benefits $^{25}$ of accepting such an offer are lower than the certainty-equivalent private cost of doing so (the certainty-equivalent award the potential rescuee reckons with paying)—i.e., only if (1) the private benefits of accepting such an offer are critically deflated while the private cost of doing so is undistorted, (2) the private cost of accepting such an offer is critically inflated while the private benefits of doing so are undistorted, or (3) the net effect of the distortions (inflations and/or deflations) in both the private benefits and the private costs of accepting such an offer is to critically deflate the profitability of doing so. Similarly, sovereign, maximizing potential rescuees will accept an offer of allocatively-inefficient rescue-services only if the certainty-equivalent private benefits the related performance should be expected to generate exceed the certainty-equivalent private cost the performance should be expected to impose on the potential rescuee-i.e., only if (1) the private benefits of accepting such an offer are critically inflated while the private cost is undistorted, (2) the private cost of accepting such an offer is critically deflated while the private benefits are undistorted, or (3) the net effect of the distortions (inflations and/or deflations) in both the private benefits and the private costs of accepting the offer is to critically inflate the profitability of doing (is to render acceptance profitable though allocatively inefficient). In order to simplify the exposition that follows, I will assume that (1) the offer in question is made in circumstances in which no binding agreement can be formed , (2) the offered rescue-service has (A) an X\% probability of rescuing \$Y in salvage that would otherwise clearly be lost (where \$Y stands for the private value of the rescued salvage to the owner of the imperiled ship) and (B) a 0\% probability of rescuing any other amount of salvage or preventing or causing any environmental loss, (3) the private cost to the potential rescuer of the offered rescue-attempt is $\$ Z$, (4) all rescue-service offerors and potential acceptors are risk-neutral, (5) the acceptance/rejection decision is made either by the owner of the imperiled ship or by someone whose goal is to maximize the interest of this shipowner, and (6) the individual who makes the acceptance/rejection decision makes the choice that does maximize the shipowner's profits.

On these assumptions, if the economy is otherwise-Pareto-perfect, the private profitability of a potential rescuee's accepting the relevant rescue-attempt offer will be undistorted (no rescue-offer acceptance/rejection misallocation will be generated if the potential rescuee is a sovereign maximizer) if the judicially-adopted

\footnotetext{
25 The certainty-equivalent private benefits equal the sum of the weighted-average benefits the rescue-attempt is expected to
} confer on the potential rescuee and the amount by which the rescue-attempt is expected to reduce his risk costs. 
compensation-formula requires courts to order potential rescuees who have received offers of rescue-services to pay successful rescuers whose offers they accepted-i.e., X\% of the potential rescuers whose offers they accepted-(100\%/X\%) \$Z. In brief, under the assumptions now being made, such an award-formula would cause the profits the potential rescuer would earn by accepting any offer of assistance to equal the allocative efficiency of his doing so since (1) it would equate the private cost of the potential rescuee's accepting the offer with the allocative cost of his doing so ([X\%][100\%/X\%][\$Z] where $\$ \mathrm{Z}$ equals not only the private but also the allocative cost of the offered rescue-attempt) and (2) the applicable otherwise-Pareto-perfect assumptions guarantee both (A) that (as just stated) \$Z equal not only the private cost but also the allocative cost of the offered rescue-attempt and (B) that \$Y equal not only the private value of the salvage that might be rescued to the potential rescuee but also the allocative benefits any successful rescue-attempt would generate). Relatedly, on our current assumptions, any compensation-award formula that required a rescuee to pay more than (100\%/X\%) \$Z to his successful rescuer would tend to misallocate resources by inducing potential rescuees to reject offers of allocatively-efficient rescue-services-in particular, would do so whenever the mandated compensation-award C exceeds (100\%/X\%) \$Z by more than the amount by which the offered rescue-service would increase allocative efficiency. ${ }^{26}$

Of course, in our actual, highly-Pareto-imperfect world, one will have to alter the reward formula to counteract the tendency of the other imperfections present in the system to distort the profitability of accepting an offer of rescue-services. Thus, in our actual economy, the following imperfections will distort the profitability of accepting the offer of rescue-services if (on our other assumptions) C is set at (100\%/X\%) \$Z:

(1) the external benefits that the acceptance of the rescue-service offer should be expected to generate because the relevant rescue-attempt should be predicted to increase the probability that imperiled-ship passenger-and-personnel lives for whose loss the owner of the imperiled ship might not be liable or might not have to pay (because he was insured or judgment-proof) would be saved;

(2) the external benefits that the acceptance of the rescue-service offer should be expected to generate because the relevant rescue-attempt should be predicted to increase the probability that cargo for whose loss the owner of the imperiled ship might not be liable or might not have to pay (because he was insured or judgment-proof) would be saved;

(3) the external benefits the acceptance of the rescue-service offer should be expected to generate because the relevant rescue-attempt should be expected to increase the probability that the imperiled ship would be saved when the owner of the imperiled ship might be insured for any such loss or might be judgment-proof;

(4) the external benefits that the acceptance of the rescue-service offer should be expected to generate because the relevant rescue-attempt should be predicted to reduce the weightedaverage-expected environmental loss the ship's imperilment would yield in circumstances in

$26 \quad$ Although the award of Cs below (100\%/X\%)\$Y could also misallocate resources by inducing potential rescuees to accept offers of allocatively-inefficient rescue-services if any such offers were made, on our current assumptions, this possibility can be ignored since no allocatively-inefficient rescue-service offers will be made under the relevant award-conditions. 
which the owner of the imperiled ship might not be liable or might not have to pay (because insured or judgment-proof for any or all of the environmental losses that resulted); and

(5) the imperfections in competition or other Pareto imperfections not yet discussed that would distort the profitability of accepting a rescue-service offer by distorting the private cost of the offered rescue-attempt or the private value of the cargo and ship that might be saved.

Since the first four imperfections listed above all tend to deflate the profitability of accepting a rescue-service offer, their presence would reduce the $\mathrm{C}$ that would eliminate any distortion in the profitability of accepting such an offer below (100\%/X\%) \$Z on our assumptions. The imperfections to which item (5) in the above list refers (1) will reduce the $\mathrm{C}$ in question to the extent that they deflate the private value to the imperiled shipowner of the cargo and ship that might be saved (since that deflation will deflate his incentives to save those assets, ceteris paribus) or to the extent that they inflate the private cost of the offered rescue-service to the potential rescuer and (2) will increase the $C$ in question to the extent that they inflate the private value of the relevant cargo and ship to the shipowner (in whose interest I am assuming the acceptance/rejection decision is being made) and to the extent that they deflate the private cost of the offered rescue-attempt (since, ceteris paribus, that deflation will cause the profits the potential rescuee can realize by accepting the rescue-service offer to be inflated).

A final reminder. The preceding analysis assumed that the individual who chose whether to accept or reject the offered rescue-attempt would make the choice that was in the interest of the owner of the imperiled ship. If the relevant chooser was trying to maximize some other objective function or was not a sovereign maximizer, one would probably have to adjust the C-formula on these accounts to award Cs that would prevent any misallocation from being generated by rescue-offer acceptance/rejection decisions.

A second type of misallocation that might be generated by $\mathrm{C}$-awards is the misallocation that results when, given the amount of resources devoted to rescuing a given imperiled ship, rescuing its cargo, passengers, and personnel, and reducing the environmental damage the relevant marine peril generates, the amount of allocative benefits generated are lower than they could have been. This type of misallocation can arise for two basic reasons: (1) because the C-formula in use rewards successful salvors different percentages of the different kinds of allocative benefits their rescue-efforts generate or (2) because the C-formula in use does not reward the salvor for altering his rescue-attempt to increase the allocative benefits other rescue-attempters generate and does not reduce the award given a seller to reflect the fact that the particular rescue-attempt he executed reduced the allocative benefits other salvors generated (by more than alternative attempts he could have made would have done). As Section 6 points out, although the current United States salvage law does reduce the award a salvor obtains if his rescue-effort unnecessarily interferes with the rescue-attempts of others, it has at least two features that cause it to generate this type of misallocation for the first of the above two reasons:

(1) it does not award salvors for reducing the environmental allocative losses the marine peril generates and does not penalize salvors for causing environmental losses (say, by releasing oil to lighten tankers to facilitate their rescue); and 
(2) it does not compensate salvors for saving lives unless they also saves ships or cargo-a feature that will deflate the profitability of saving lives when no other type of salvage is rescued and will inflate the profitability of saving a cargo or ship when one or more lives have been or could be saved.

In any event, to prevent this type of misallocation from being generated, the C-award formula should not treat different kinds of allocative benefits differently and should make a successful salvor's award depend inter alia on the effects his attempt had on the allocative-efficiency gains generated by the other rescue-attempts made on the salvage in question.

A third type of misallocation that C-awards can affect is the misallocation that is generated because the wrong number of rescue-attempts is made on a given imperiled ship, given the fixed-cost decisions that have been made. In an otherwise-Pareto-perfect world (in which the potential rescuer would make the choice that was in his best interest, the private variable cost of his rescue-attempt would equal its allocative variable cost, and the private benefits his rescue-attempt would confer on the owner of the imperiled ship would equal the allocative benefits it would generate), the C-award that would eliminate any misallocation of this kind would be an award equal to the "market value”27 of any rescued salvage, which will equal the private benefits the rescueattempt conferred on the owner of the imperiled ship since, in an otherwise-Pareto-perfect world, he would either own everything that was saved or would have to compensate the owners of the relevant salvage fully for any loss they sustained and (2) there would be no difference between the market value of the salvage and its value to its owner. Before explaining why-in our actual, highly-Pareto-imperfect world—such a $\mathrm{C}$ would be unlikely to eliminate any misallocation of this kind (by equating the ex ante profitability and allocative efficiency of any possible rescue-attempt), I want to point out that the $\mathrm{C}$ in question will almost always substantially differ from the $\mathrm{C}$ that would prevent potential rescuees from making allocatively-inefficient rescue-offer acceptance/rejection decisions in a Pareto-perfect-world-viz., a C equal to the product of the private cost of the rescue-attempt in question and (100\% divided by the probability that this rescue-attempt would be successful). In other words, before proceeding, I want to point out that, in a Pareto-perfect world (and almost certainly in our actual, highly-Pareto-imperfect world), no $\mathrm{C}$ will be able to prevent both these types of misallocation-that, even if the $\mathrm{C}$ in question would affect no other type of misallocation, the most-allocatively efficient $\mathrm{C}$ would be the $\mathrm{C}$ that generated the smallest amount of marine-peril-related misallocation that any $\mathrm{C}$ would generate, not the $\mathrm{C}$ that eliminated all marine-peril-related misallocation.

In any event, even if I assume that the decision to offer to make and to actually make a rescue-attempt would be the decision that would maximize the interest of the potential salvor, various Pareto imperfections would cause the profitability of a rescue-attempt to the potential rescuer to diverge from its allocative efficiency 
when the compensation he would receive if successful equaled the market value of the salvage he rescued. At lest four sets of such imperfections are worth distinguishing:

(1) the net environmental allocative benefits the rescue-attempt will generate, which will (in general) be external to the owner of the imperiled ship and in any event would not be reflected in any award whose calculation ignored their existence;

(2) the externalities the rescue-attempt will generate because-even if no alternative, otherwiseequally-allocatively-efficient rescue-attempt the salvor in question could have made would have generated a smaller reduction in the ex ante allocative efficiency of other salvors' rescueattempts - the successful rescue-attempt did reduce the ex ante allocative efficiency of the rescue-attempts others made; ${ }^{28}$

(3) the external costs the rescue-attempt will generate because, even if no-one rescued the salvage in question, it might not have been lost; ${ }^{29}$ and

$28 \quad$ Assume for simplicity that rescue-attempts come in only one form and that at most one rescue-attempt will be successful. If the probability that a given body of salvage will be rescued increases less than proportionately with the number of rescue-attempts that are made, each successive rescue-attempt that is made will reduce the probability that the other rescue-attempts will be successful. To see why this externality can cause misallocation, assume that (1) the private and allocative value of the salvage is $\$ 1,000,000$, (2) the private and allocative cost of each rescue-attempt is $\$ 200,000$, (3) either all or none of the salvage will be rescued, (4) the probability of rescue is $40 \%$ if one rescue-attempt is made, $65 \%$ if two rescue-attempts are made, $75 \%$ if three rescue-attempts are made, $81 \%$ if four rescue-attempts are made, and $85 \%$ if five rescue-attempts are made, (5) if more than one rescue-attempt is made, each rescueattempter will be equally likely to succeed, (6) everyone involved is risk-neutral, and (7) a successful rescue-attempter will be awarded the full value of the salvage he rescues- $\$ 1,000,000$. On these assumptions, four rescue-attempts will be made, the allocatively-efficient number of rescue-attempts will be two, and the resulting misallocation will be $\$ 140,000$. To see why four rescue-attempts will be made, note that if four are made each attempter will perceive ex ante that he has a $20.25 \%=(1 / 4) 81 \%$ chance of securing the \$1,000,000 award and hence the revenue each will expect his rescue-attempt to yield on the weighted average ([20.25\%]\$1,000,000=\$202,500) will exceed the private cost of his attempting a rescue $(\$ 200,000)$, while if five rescue-attempts are made each attempter will perceive ex ante that he has a $17 \%=(1 / 5) 85 \%$ chance of receiving the $\$ 1,000,000$ award and hence the revenue each will expect his rescue-attempt to yield on the weighted average $([17 \%] \$ 1,000,000=\$ 170,000)$ will be lower than the private cost of his making the rescue-attempt $(\$ 200,000)$. To see why the number of rescue-attempts that will be most allocatively efficient is two, note that (1) the first rescue-attempt will yield allocative benefits of (40\%) $\$ 1,000,000=\$ 400,000$ and allocative costs of $\$ 200,000$, (2) the second rescue-attempt will yield allocative benefits of $(65 \%-40 \%) \$ 1,000,000=\$ 250,000$ and allocative costs of $\$ 200,000$, (3) the third rescue-attempt will yield allocative benefits of $(75 \%-65 \%) \$ 1,000,000=\$ 100,000$ and allocative costs of $\$ 200,000$, and (4) the fourth rescue-attempt will yield allocative benefits of (81\%-75\%) $\$ 1,000,000=\$ 60,000$ and allocative costs of $\$ 200,000$. The last two results imply that in the situation in question the last two rescue-attempts will have misallocated resources by $\$ 100,000$ and $\$ 140,000$ respectively-i.e., by a total of $\$ 240,000$. The reason that the third rescue-attempt was ex ante profitable despite its allocative inefficiency-viz., yielded ex ante profits of 25\%(\$1,000,000)-\$100,000=\$50,000 while decreasing ex ante allocative efficiency by $\$ 100,000$ - is that the allocative cost the third rescue-attempt generated by reducing the probability that the first two rescue-attempters would be successful by $15 \%$ from $65 \%$ to $75 \%-25 \%=50 \%$ (the attendant reduction of $\$ 150,000$ in the $e x$ ante allocative benefits the first two rescue-attempts should have been predicted on the weighted average to generate was external to the third rescue-attempter: this externality accounts of the $\$ 150,000$ difference between the $\$ 50,000$ ex ante profits the third rescueattempt should have been predicted to yield and the $\$ 100,000$ ex ante allocative-efficiency loss it should have been predicted to generate. Similarly, the reason that the fourth rescue-attempt was ex ante profitable despite its allocative inefficiency-viz., yielded ex ante profits of $(20.25 \%) \$ 1,000,000-\$ 200,000=\$ 2,500$ while decreasing ex ante allocative efficiency by $\$ 140,000-$ is that the allocative cost the fourth rescue-attempt generated by reducing the probability that one of its three predecessors would succeed by $14.25 \%$ from $75 \%$ to $60.75 \%=(3 / 4)(81 \%)$ (the attendant reduction of $\$ 142,500$ in the ex ante allocative benefits the first three rescueattempts should have been predicted on the weighted average to generate) was external to the fourth rescue-attempter: this externality accounts for the $\$ 142,500$ difference between the $\$ 2,500$ ex ante profits the fourth rescue-attempt should have been predicted to yield and the \$140,000 ex ante allocative-efficiency loss it should have been predicted to generate. I should perhaps note that, in the situation described, any $\mathrm{C}$ at or above $\$ 615,384(8 / 13)$ but below $\$ 800,000$ would induce the allocatively-efficient number of rescueattempts to be made. Thus, any $\mathrm{C}$ in that range would induce at least two rescue-attempts to be made because a $32.5 \%$ chance of collecting at least $\$ 615,384(8 / 13)$ would be worth at least $\$ 200,000$ to a risk-neutral potential rescuer, and any C below $\$ 800,000$ will not induce three rescue-attempts to be made because a $25 \%$ chance of collecting less than $\$ 800,000$ is worth less than $\$ 200,000$ - the cost of the rescue-attempt-to a risk-neutral potential rescuer (recall that if three rescue-attempts are made the probability that one of them will be successful is $75 \%$ so that each attempter will reckon with a $25 \%$ chance of being successful).

29 To demonstrate the relevance of these externalities, one need only alter the example discussed in note 27 in two ways: (1) assume that there is a $10 \%$ chance that the salvage involved in that case would not be lost if no-one attempted a rescue and (2) alter its 
the imperfections in competition and various other types of Pareto imperfections not yet considered (including the possible difference between the value of salvage to its owner and its market value) that would distort the private (variable) cost of the rescue-attempt or the market value of the relevant salvage and hence (except fortuitously) the profitability of the rescueattempt in an otherwise-Pareto-perfect world if the $\mathrm{C}$ were set at the market value of the rescued salvage.

Obviously, to induce sovereign, maximizing potential marine-rescuers to make allocatively-efficient decisions about executing rescue-attempts that would generate environmental allocative benefits, one would have to offer successful rescuers who had made attempts of this kind Cs that exceed the market value of the salvage they rescued by an appropriate amount, other things being equal; to induce sovereign, maximizing potential marinerescuers to make allocatively-efficient decisions about executing rescue-attempts that would generate the types of allocative external costs discussed in items (2) and (3) in the preceding list, one would have to offer successful rescuers who had made attempts of this kind Cs that were appropriately lower than the market value of the salvage they rescued, other things being equal; and to induce sovereign, maximizing potential marinerescuers to make allocatively-efficient decisions about executing rescue-attempts whose profitability would be distorted by other types of Pareto imperfections than those already considered, one would have to increase or decrease the Cs they would be awarded above or below the market value of what they rescued to offset the profit-distortions these other types of imperfections would generate.

The fourth "type" of marine-peril-related misallocation that might be generated is the misallocation that could be generated by the various fixed-cost decisions that marine-salvors make-inter alia, decisions to construct marine-salvage ships, to alter or equip other sorts of ships to increase their marine-salvage capabilities, to hire and train personnel to perform marine-salvage functions, and to deploy ships in positions that increase their marine-salvage opportunities. Although one could investigate the C-formula that would make it profitable for potential marine salvors to make the set of fixed-cost decisions that would be most allocatively efficient if all salvage ships that were constructed, all non-salvage ships that were adapted to increase their salvaging capabilities, and all relevant personnel would be deployed and then used as allocatively

second assumption to make the private and allocative cost of each rescue-attempt that could be made on the salvage in question $\$ 350,000$ rather than $\$ 200,000$. On these assumptions, one rescue-attempt will be made if a successful salvor would receive the full market-value of what he had saved (and the potential rescuee had no opportunity to reject the offer of a rescue-attempt). This conclusion reflects the fact that if one rescue-attempt were made the weighted-average expected award to the rescue-attempter would be $40 \%(\$ 1,000,000)=\$ 400,000$, which exceeds the private cost of that attempt $(\$ 350,00)$, while if two rescue-attempts were made the award that each rescue-attempter would expect to obtain on the weighted average- $(1 / 2)(65 \%) \$ 1,000,000=\$ 325.000$ — would be lower than the private cost of his rescue-attempt. Unfortunately, on the assumptions of the current example, the rescue-attempt that would be made would be allocatively inefficient—viz., would generate weighted-average-expected allocative benefits of $\$ 300,000$ by increasing the probability that the $\$ 1,000,000$ of salvage that was at risk would not be lost from $10 \%$ to $40 \%$ and allocative costs of $\$ 350,000$. The difference between the $\$ 50,000$ in profits the rescue-attempt in question should be expected to generate ex ante and the $\$ 50,000$ in allocative inefficiency it should be expected to generate is the $\$ 100,000$ in external costs it would generate given the C on offer because there was a $10 \%$ probability that the salvage in question would not have been lost had no attempt been made to rescue it. Other things being equal, to prevent this type of misallocation, one would have to reduce the $\mathrm{C}$ the court awarded by the amount of salvage one should expect on the weighted average not to have been lost had no attempt been made to rescue it: in effect, such a reduction would internalize to the potential rescuer what would otherwise be the external cost his rescue-attempt would impose on the salvage-owner. 
efficiently as is possible, the more relevant question is: "Which C-formula would produce the most-allocativelyefficient set of potential-marine-rescuer fixed-cost decisions, given the way in which each possible set of constructed or adapted salvors and their personnel would actually be deployed and used?”

I will assume at the outset that all marine salvors are identical professional salvors and that the economy is otherwise-Pareto-perfect. The consequences of relaxing these unrealistic assumptions will be examined at the end of the relevant discussion.

I begin with two fairly-obvious observations. First, the C-formula that would prevent marine-salvor fixed-cost-decision misallocation would have to yield salvage awards that would give salvors enough operating profits across all the rescue-attempts they made to cover the fixed costs they would incur if the mostallocatively-efficient set of marine-rescue fixed-cost decisions were made-i.e., would have to exceed the product of (the market value of the salvage they rescued) and (100\% divided by the ex ante probability that they would rescue any salvage [if for expositional reasons we continue to make the simplistic assumption that ex ante the potential rescuer will believe that he has an $\mathrm{X} \%$ chance of rescuing $\$ \mathrm{Z}$ in salvage and no chance of rescuing any other amount of salvage]). Second, the C-formula in question will not in general be the formula that causes each salvor's weighted-average-expected salvage-awards to exceed his variable rescue-costs by the same percentage by which his fixed rescue-costs exceed his total variable rescue-costs: if courts awarded Cs that enabled all existing salvors to earn a normal return on their fixed costs, those Cs (1) would perpetuate excessive investment in marine-salvage capabilities from the perspective of allocative efficiency if too many resources were devoted to marine-salvage-capabilities investment from that perspective prior to the relevant awards being made and (2) would perpetuate inadequate investment in marine-salvage capabilities from the perspective of allocative efficiency if too few resources were devoted to marine-salvage-capability investment from that perspective prior to the relevant awards being made.

As these two observations imply, in order to determine the percentage by which the total amount of awarded Cs should exceed the total variable rescue costs the salvor incurred, the analyst would have to know not the ratio of existing-salvor fixed costs to existing-salvor total variable costs but the ratio of marine-salvor fixed to total variable cost that would prevail if the most-allocatively-efficient set of marine-salvor fixed-cost decisions were made. Obviously, to determine this latter ratio, the analyst would have to do a complete analysis of the way in which the C-award that would eliminate marine-salvor fixed-cost-decision misallocation would affect all other decisions that would influence the allocative efficiency of marine-salvor fixed-cost-decisionsi.e., would influence not only marine-salvor variable-cost (rescue-attempt) decisions but also potential-rescuee marine-peril-avoidance decisions and rescue-service-offer acceptance/rejection decisions.

I hasten to note that these analyses will take account of the unfortunate fact that the C-award formula that will eliminate marine-salvage fixed-cost-decision misallocation, given the other decisions it will induce potential marine salvors and potential marine rescuees to make, will almost certainly simultaneously cause marine salvors to make allocatively-inefficient rescue-attempt decisions and potential marine rescuees to make 
allocatively-inefficient marine-peril-avoidance and rescue-service-offer acceptance/rejection decisions. I hasten to note as well that, even on the simplifying assumptions on which the preceding discussion was based, the second-best-allocative-efficiency analysis of the C-award formula that would eliminate marine-salvor fixedcost-decision misallocation would be both extremely complex and very difficult. ${ }^{30}$

I will now relax the two simplifying assumptions made at the beginning of this discussion. First, even when the set of marine-salvor fixed-cost decisions is allocatively efficient, the ratio of fixed to total variable cost of different marine salvors will vary substantially. More specifically, the ratio in question (1) will be highest for professional salvors, next highest for semi-professional salvors, and lowest (zero) ${ }^{31}$ for casual salvors and (2) may vary considerably within the professional-salvor and semi-professional-salvor categories. Obviously, this reality implies that the C-formula that will eliminate marine-salvor fixed-cost-decision misallocation will be more complicated than would otherwise be the case-will have to take account of intersalvor variations in the relevant fixed-cost to total-variable-cost ratio. Second, as noted in the discussion of the other types of marine-peril-related misallocation that can be generated, the economy is highly-Pareto-imperfect. Various Pareto imperfections will affect the analysis of the C-formula that will eliminate marine-salvor fixedcost-decision misallocation in at least two ways:

(1) by complicating the analysis of the marine-salvor fixed-cost decisions that would be most allocatively efficient and

(2) by making it necessary for the analyst of the C-award formula that would eliminate all marinesalvor fixed-cost-decision misallocation to take account of any government subsidization of the relevant fixed-cost expenditures or any license fees the government charged professional or semi-professional marine salvors.

The first of these two realities requires some elaboration. Pareto imperfections will complicate the analysis both of the total amount of fixed-cost expenditures that will be allocatively efficient for marine salvors to make and of the particular fixed-cost expenditures that will be allocatively efficient for them to make, given the total investment made in marine-salvage "capabilities.” Pareto imperfections will affect the total amount of fixed-cost expenditures that will be allocatively efficient (1) by distorting the private cost of the resources the fixed-cost expenditures “consume,” (2) by distorting the private value to its owners of the salvage such fixedcost expenditures enable marine salvors to rescue, (3) by externalizing from the marine salvor any benefit his fixed-cost expenditures generate by causing him to prevent environmental allocative losses, and (4) by influencing the impact of his fixed-cost expenditures on the amount of misallocation generated by his rescueattempt decisions and various marine-peril-related decisions made by potential rescuees. Pareto imperfections will affect the C-formula that will prevent marine salvors from making less-allocatively-efficient fixed-cost

$30 \quad$ Neither Landes and Posner nor the HARVARD Note (which makes many improvements on Landes and Posner) manifest any awareness of the complexity and difficulty of the analysis one would have to execute to identify "the most-allocatively-efficient set of fixed-cost marine-salvage decisions" in any sense in which that concept might be defined. See, e.g., HARVARD Note at 1907-08.

31 I am assuming that, by definition, "casual salvors" are salvors who have not adapted their ship, altered the selection or training of their ship’s personnel, or changed their ship’s deployment in any way to increase the amount of salvage they rescue. 
expenditures than they could have made given their total investment in marine-salvage "capabilities"

because Pareto imperfections may yield different distortions in the private cost of different sorts of fixed-cost expenditures - in particular, different distortions in the private cost of constructing salvage ships, altering nonsalvage ships, equipping either sort of ship, hiring and training salvage-operation personnel, and deploying salvage-capable ships in particular ways - and (2) because the type of fixed-cost expenditure that is made may affect the type of salvage that is rescued or the balance between salvage rescued and environmental losses prevented and the operative Pareto imperfections may yield different distortions in the private value to their owners of the different sorts of salvage that different fixed-cost expenditures would cause to be saved and/or in the private value to the salvor of preventing environmental losses. For all these reasons, the C-formula that will eliminate marine-salvor fixed-cost-decision misallocation will have to take account of the nature of the fixedcost expenditures the salvor in question made or should have made from the perspective of allocative efficiency.

I want to close this discussion by emphasizing two points. First, the C-award formula whose application would eliminate marine-salvor fixed-cost-decision misallocation would focus not just on the expenditures of the successful salvor in the case at hand and the operating profits the award its use would produce in the instant case but on the fixed-cost decisions of all marine salvors and potential marine salvors, on the amount of such expenditures that would be allocative efficient, and on the amount of salvage each salvage-boat or salvageadapted non-salvage boat would rescue. Second, except fortuitously, the C-award formula whose application would eliminate marine-salvor fixed-cost-decision misallocation would not eliminate marine-salvor rescueattempt-decision misallocation, potential-rescue avoidance-decision misallocation or potential-rescuee rescueservice-offer acceptance/rejection-decision misallocation.

The final type of marine-peril-related misallocation whose magnitude will be affected by marine-salvage awards is potential-rescuee marine-peril-avoidance-decision misallocation. With two exceptions, the analysis of the C-award formula that would eliminate this type of misallocation is identical to the analysis of the Caward formula that would eliminate potential-rescuee rescue-service-offer acceptance/rejection-decision misallocation:

(1) the C-formula that would prevent potential-rescuee avoidance-decision misallocation (if all potential rescuees were sovereign maximizers) would have to take account of the effect that such decisions have on the fixed allocative costs that potential salvors generate as well as on the amount of variable allocative costs rescue-attempts generate, the allocative value of salvage that is lost, and the environmental allocative costs that marine peril generates; and

(2) the C-formula that would prevent potential-rescuee avoidance-decision misallocation (if all potential rescuees were sovereign maximizers) would have to take account of the distortion in the private cost of potential-rescuee avoidance-moves that was generated by the operative Pareto imperfections.

Hence, in an otherwise-Pareto-perfect world in which everyone was risk-neutral, the C-award formula that would eliminate potential-rescuee marine-peril-avoidance-decision misallocation would equal the sum of (1) the 
product of (the variable cost of the rescue-attempts made) and (100\%/[the probability that these attempts would be successful]) and (2) (the amount by which the potential rescuee's activities increased the fixed-cost marine salvage expenditures of all marine salvors divided by the number of times the rescuee was the object of a successful marine-rescue attempt-i.e., the number of times the rescuee had to compensate a marine salvor). And, in our actual, highly-Pareto-imperfect world, the C-formula that would prevent sovereign, maximizing potential rescuees from making misallocative marine-peril-avoidance decisions would have to be adjusted to offset the distortion in the profitability of such decisions that the operative Pareto imperfections would generate by distorting the private cost of the fixed-cost-of-rescuing and variable-cost-of-rescuing expenditures the avoidance-move in question would deter, the private value to the potential rescuee of the salvage whose loss the avoidance-decisions in question would prevent, the private value to the potential rescuee of the environmental allocative losses the avoidance-decisions in question would prevent, and the private cost of the avoidancedecisions themselves to the potential rescuee in question.

The same two conclusions that I have reached about all the other types of marine-peril-related misallocation this section has discussed will apply equally forcefully in relation to potential-rescuee marineperil-avoidance-decision misallocation:

(1) the analysis of the C-formula that will prevent this type of misallocation will be complicated and difficult; and

(2) the C-formula that will prevent this type of misallocation will almost certainly not prevent the other types of misallocation that may be associated with marine perils.

I have so far discussed the various C-formulae that would prevent each of the types of marine-perilrelated misallocation that judicially-ordered marine-rescuee-to-rescuer compensation-awards could affect. In order to identify the C-formula that would be the most-allocatively-efficient formula a judicial system could use, an analyst would have to determine in addition the amount of marine-peril-related misallocation of each relevant type that any given C-formula would generate because it differed (if it did differ) from the formula that would eliminate misallocation of that type and, derivatively, the total amount of marine-peril-related misallocation each possible C-formula would generate. For the former purpose, the analyst would have (1) to calculate the aggregate distortion in the profitability of the various decisions in each category that the different possible C-formulae would generate, (2) to ascertain the way in which the relevant potential-marine-rescuer and potential-marine-rescuee choices would be distorted by the relevant chooser's non-sovereignty and nonmaximization-inter alia, the difference between these choosers’ perception of the profitability of the relevant choices and those choices’ actual profitability, and (3) to determine the number of choices in each category whose allocative efficiency was oppositely signed to and absolutely smaller than the sum of the actual distortion in the profitability of the relevant choices and the "equivalent-dollar distortion" in their profitability that one might say was caused by the relevant chooser's non-sovereignty and non-maximization-i.e., the number of choices in each category whose profitability would be critically distorted if the C-formula in question were 
used-and the average allocative efficiency or allocative inefficiency of those choices in the relevant category whose profitability would be critically affected by the C-formula in question.

I want to close this discussion of the approach to marine-salvage awards that would be second-bestallocatively-efficient for a judicial system to take with a comment on one of its central findings—viz., that no award will be able to eliminate all of the various types of misallocation with which marine peril may be associated, that the most-allocatively-efficient set of C-awards a judicial system could make would not eliminate all marine-peril-related misallocation. The comment is that this conclusion exemplifies the following truism: in order to control X decisions, a decisionmaker must have X policy instruments. A judicial system that is authorized solely to require marine rescuees to compensate those of their rescuers who have not negotiated a binding price for their services cannot eliminate marine-peril-related misallocation by making appropriate compensation-awards because, regardless of how complicated it makes the formula it uses to determine those awards, the number of policy instruments at its disposal will be smaller than the number of decisions it will need to control to eliminate all marine-peril-related misallocation. Even on the second-best-allocativeefficiency-analysis assumptions that perfect theoretical analyses can be costlessly executed and perfect data can be costlessly collected and analyzed, such compensation-awards would have to be supplemented with other policies such as marine-salvor subsidies or license fees for misallocation to be eliminated.

\section{The Approach That Would Be Third-Best-Allocatively-Efficient for a Judicial System to Take to} Marine-Rescuee-to-Rescuer Compensation-Award Cases

Third-best-allocative-efficiency analysis differs from second-best-allocative-efficiency analysis in that it takes account both of (1) the cost and probable imperfectness of all conceptual analysis and (2) of the cost and imperfectness of data. Thus, someone who was trying to execute a third-best-allocative-efficiency analysis would formulate and carry out a theoretical analysis of a particular theoretical issue that a second-bestallocative-efficiency analysis would perfectly analyze if and only if he thought ${ }^{32}$ that the allocative cost of his doing so was lower than the amount by which the analysis in question would increase the allocative efficiency of implementing the policy he would conclude would be best to implement from the perspective of allocative efficiency. Similarly, someone who was trying to execute a third-best-allocative-efficiency analysis would collect and analyze data or additional data on some parameter that his theoretical analysis showed would affect the content of the most-allocatively-efficient policy-recommendation he could make if and only if he thought that the allocative cost of the relevant data and its analysis was lower than the amount by which that data would

\footnotetext{
32 I use the word "thought" to elide a conceptual problem that makes any operationalization of the concept "third-bestallocative-efficiency analysis" problematic_viz., the infinite-regress problem that arises in relation to the following series of questions: "How much time and effort should someone who wants to execute a third-best-allocative-efficiency analysis devote to determining whether he should try to formulate and think through a particular theoretical issue (or collect some data)?”, “How much time and effort should such an individual devote to determining the time and effort he should devote to determining the time and effort he should devote to determining the time and effort he should devote to determining whether he should try to formulate and think through a particular theoretical issue (or collect some data)?”, etc.
} 
increase the allocative efficiency of implementing the policy he would conclude would be best to implement from the perspective of allocative efficiency. I have four preliminary observations to make about some determinants of the extent to which the analysis of some issue that would be TBLE for a government decisionmaker to make would be less complicated than the analysis that would be SBLE for him to execute, one point about a reason why ceteris paribus TBLE analysis will be more complicated than SBLE analysis, and four tentative suggestions about the difference between the approaches to marine-rescuee-to-rescuer compensationaward-formula determination that would be second-best and third-best allocatively efficient for a judicial system to adopt.

The four preliminary observations are all general-i.e., apply to the concrete difference between secondbest and third-best allocative-efficiency analyses of all issues. These observations are also all obvious. First, the extent to which the TBLE analysis of any issue will be simpler than the SBLE analysis of that issue will depend in part on the general intellectual ability, specific skills, staff, procedures, and budgets of the individuals and institutions that would have to make the decision at which the analyses in question would be directed. Second, these factors will be less important if the decisionmakers or decisionmaking institutions in question can contract out the necessary work-e.g., if a court or judicial system can hire a court master to execute the theoretical or empirical analyses in question. Third, although the factors listed in the first preliminary observation will be less important when the tasks in question can be contracted out, they will still have some significance in such circumstances: decisionmakers and decisionmaking institutions will differ in their abilities to hire “cost-effective" outside contractors, to monitor their work, and to assess and implement their conclusions, and such differences may affect the allocative efficiency of their hiring outsiders at all and will often affect the character and quantity of the theoretical and empirical analyses that it will be third-bestallocatively-efficient for decisionmakers to hire outsiders to execute. Fourth, the extent to which the approach that will be TBLE for a given institution to take to some policy-issue will be simpler than its SBLE counterpart will depend in part on the extent to which it can take advantage of relevant theoretical work and empirical analyses others have already completed. Most of the theoretical analyses and data that a SBLE analysis of marine-rescuee-to-rescuer compensation-awards would respectively execute and collect would also be relevant for the analysis of the allocative efficiency of other policies—not just of accident and pollution policies and finders and Good Samaritan policies but also of antitrust, regulated-industry, intellectual-property, and tax policies. A policy-making system that relied on decisionmakers to execute such analyses and collect such data when it would be allocatively efficient for them to do so if their efforts would not be valuable to other decisionmakers will be allocatively inefficient (1) because the externalities that would be generated in such a system would tend to cause each individual decisionmaker to do too little work of the relevant kind and (2) because individual decisionmakers and decisionmaking institutions might be unable to take advantage of all available economies of scale in doing the relevant theoretical and empirical work. I should say that, at present, the governments of the United States do virtually no theoretical work on second-best or third-best allocative- 
efficiency analysis and collect very little data on Pareto imperfections themselves. Nor do they provide significant support for outsiders to do such theoretical and empirical work. Instead of spending billions of dollars on classifying industries and collecting market-aggregated data that has virtually no policy significance, ${ }^{33}$ the United States government should support theoretical work on allocative-efficiency analysis and empirical work on Pareto imperfections. If such work were done and its conclusions made available to relevant decisionmakers, TBLE analysis would be much closer to SBLE analysis, and government decisionmakers would be more able to determine the policy-choices that would be allocatively efficient (and, I hope, more able to make policy-choices that are desirable because more allocatively efficient). ${ }^{34}$

I also want to make a specific point about a way in which (against the run of general form) TBLE analyses will be more complicated than SBLE analyses: TBLE analyses will have to take account of theoretical and empirical information-imperfections that will not trouble the SBLE analyst. Thus, the person who is executing a TBLE analysis will have to recognize that his conclusion about the identity of the policy-option available to him or the decisionmaker who has hired him that is most allocatively efficient may be wrong, he will have to identity the policy that minimizes policy-error misallocation rather than the policy he thinks is most likely to be allocatively efficient-in the marine-salvage-award context, to determine the C-formula that will minimize C-award-error misallocation rather than C-award errors (the difference between the allocativelyefficient C-award and the actual C-award). If, for example, a marine-salvage-award analyst has reason to believe that awards that exceed the most-allocatively-efficient award by a given amount are likely to be more misallocative than awards that fall below that most-allocatively-efficient sum by the same amount, it will be TBLE for the analyst to recommend an award-formula that produces Cs that are on the high side. Obviously, the fact that the information-imperfections that TBLE analysis takes into account make this additional calculation part of a TBLE analysis implies that TBLE analysis will tend to be more complicated on this account than SBLE analysis.

Finally, I have four observations to make about the simplifications that would probably be TBLE for a judicial system to make in the approach it takes to developing a C-formula for marine-rescuee-to-rescuer compensation awards. The first relates to the relevant theoretical analysis: nothing about marine-salvagecompensation-award analysis disposes me to depart from my general (admittedly self-serving) conclusion that it will be allocatively efficient to think through the relevant theoretical issues as thoroughly as possible. The remaining observations relate to the relevant empirical work. I should admit at the outset that (1) my own lack of experience at collecting data on the relevant Pareto imperfections and various private cost and benefit figures that a SBLE analysis would take into account, (2) the paucity of independent private studies of these parameters from whose execution I might be able to learn, and (3) the virtual absence of government studies of these

33 See Richard S. Markovits, On the Inevitable Arbitrariness of Market Definitions, 2002 THE ANTITRUST BULL. 571 (2002).

34 I do not deny the political impediments to public decisionmakers' making desirable choices. Nor do I deny the reality that from various legitimate value-perspectives, the desirability of some or all policy-choices will not be affected at all by their allocative efficiency. On the latter point, see Markovits, op. cit supra note 1. 
parameters all reduce my ability to say much of value about the specific simplifications that would be TBLE for a judicial system to make in the approach it takes to determining the formula member-courts will use to calculate marine-rescuee-to-rescuer salvage-awards (if it could appoint a court master to do the relevant work or if it could not contract out this work in some such way).

The second is an admission against interest: ${ }^{35} \mathrm{I}$ fear or suspect that-given the characteristics of judges and judicial organizations, the failure of government to execute or sponsor the relevant theoretical and empirical analyses, the failure of Economics Departments to train their students to do second-best and third-best allocative-efficiency analyses, and the paucity of economists who know how or are inclined to execute such analyses - it may be TBLE for courts to ignore the way in which imperfections in competition will distort the private value of rescued salvage, the private fixed and variable cost of marine-rescue attempts, and the private cost of potential-marine-rescuee avoidance-moves.

The third is that it will probably be TBLE for a judicial system that is trying to develop a TBLE marinerescuee-to-rescuer compensation-award formula to ignore the possibility that the affected marine salvors and rescuees may make relevant human errors. In part, this conclusion reflects the fact that those actors are (by and large) sophisticated decisionmakers. In part, it reflects the fact that the relevant errors are hard to detect and may not be biased in any particular direction. And in part, reflects the possibility that paying attention to particular errors may give parties an incentive to make them.

My fourth suggestion is self-serving in the same sense that my first such suggestion was a proposal against interest. I suspect that it would be TBLE for a judicial system to take account of virtually all of the other complexities I have shown would be considered by a second-best-allocative-efficiency analysis.

5. Some Comments on the Sense in Which the TBLE Marine-Rescuee-to-Rescuer Compensation-Award Formula Is Allocatively Efficient

This section makes three points about the allocative efficiency of the TBLE formula for marine-rescueeto-rescuer compensation-awards. First, unless the analyst who derived this formula was extremely lucky as well as able, the formula will not minimize the amount of misallocation caused by the marine-peril-related choices made by potential marine rescuers and rescuees. This conclusion reflects the fact that the analysis that generated the formula in question was TBLE — that the analyst stopped doing theoretical work and collecting and processing data not at the point at which he was certain that his formula-recommendation would be perfect but at the point at which he thought that the allocative benefits that further work of the relevant kinds would yield by enabling him to improve his formula-recommendation would be lower than its allocative cost.

Second, for reasons that the two preceding sections should have made clear, even if one takes account of the fact that the policy-package response that would constitute the government's TBLE response to marine peril supra. 
would be different from and, quite likely, less complex than the policy-package response to marine peril that would be SBLE for the government to make, it is extraordinarily unlikely that—standing alone-a policy of creating common-law-type courts and instructing them to require marine rescuees to pay successful marine rescuers who have not been able to negotiate binding prices for their services sums that are derived by applying the formula that would be TBLE for such courts to employ for this purpose would constitute the TBLE response the government could make to marine peril.

Third, a policy of obligating such courts to order any marine rescuee who has been sued by a salvor who has rescued some or all of its salvage in circumstances in which the salvor could not negotiate a binding price for his rescue-services might well be part of the TBLE response a government could make to marine peril. A decision to create such a cause of action would have at least the following four advantages over such alternatives as the combination of government-financed awards paid to successful marine salvors whose conduct increased allocative efficiency in some sense and government civil or criminal penalties levied on potential marine rescuees whose marine-peril-avoidance-choice rejections and marine-rescue-offer rejections decreased allocative efficiency in some sense:

(1) it would provide marine rescuees with incentives to provide government decisionmakers with information about the probability that their ship, cargo, passengers, and officers would not have been lost had no-one attempted a rescue and various details about the rescue-attempts that were made on their salvage (for example, about the extent to which they interfered with each other);

(2) it might save allocative transaction costs by combining two proceedings into one;

(3) to the extent that the fines that would be collected would be lower than the awards that would be given, it would obviate the government's generating allocative costs to finance the relevant short-fall;

(4) it would reduce the misallocation and other bad consequences that a government-run system of awards and penalties would generate if those who administered it were financially or politically corrupt; and (almost certainly least importantly)

(5) to the extent that members of the public place a positive value on the beneficiaries' of a marine rescue compensating their rescuer, it will generate distributional-preference-based external benefits on this account.

On the other hand, in comparison with such an alternative approach, a decision to create such a cause of action would have at least the following four disadvantages:

(1) it would sacrifice any skill and economies-of-scale-related efficiencies that might be secured by creating a specialized institution that concentrated on these issues and heard all cases of the relevant kind;

(2) by relying on the successful salvor who was the plaintiff in an individual case to provide information about the rescuees' allocatively-inefficient marine-peril-avoidance-decision conduct, it would misallocate resources not just because the individual salvor might be less adept than a government investigator at securing such information but also because the private value of such information to the individual plaintiff (the amount by which it would increase the award he 
received) would almost certainly be lower than the allocative value of that information-the amount by which the prospect of its discovery and use would increase the allocative efficiency of the awards that are made;

(3) by relying on marine rescuees to counter the salvage-operation-investment, variable-cost of rescue-attempt, ex ante probability of success, and rescue-opportunity claims of their rescuers, it would misallocate resources not just because the individual rescuee might be less adept at securing such information than a government investigator would be but also because the private benefit to a marine rescuee of challenging his rescuer's claims on these issues would be likely to be lower than the allocative value the prospective provision of such information would generate by affecting the allocative efficiency of the awards that are made;

(4) to the extent that the fines that would be collected would exceed the awards that would be made, it would reduce the misallocation the government would generate when financing its expenditures (by reducing the government's expenditures).

Although this set of observations about the allocative-efficiency advantages and disadvantages of granting successful marine salvors a legal right to secure compensation from their rescuees is far too off-hand to deserve much weight, I would not be surprised if a decision to establish such a cause of action would be part of a TBLE policy-package response to marine peril, at least if jurisdiction for such cases were centralized or perhaps assigned to a specialist court.

6. The Third-Best-Allocative-Efficiency of Our Current Judge-Announced-and-Applied Marine-Rescueeto-Rescuer-Compensation Law

This section will examine whether our current judge-announced positive marine-salvage law is thirdbest-allocatively-efficient. Before proceeding to this task, I want to make six preliminary observations. First, the discussion that follows is not based on any assumption that the internally-correct way to resolve suits for compensation brought against the owner of an imperiled ship by a plaintiff who had tried to rescue that ship and/or the cargo, passengers, and personnel it carried without being able to negotiate a binding price for the relevant rescue-service would be to apply a compensation-formula whose derivation and use would be thirdbest-allocatively-efficient. ${ }^{36}$

Second, the account of judge-announced marine-rescuee-to-rescuer-compensation law on which this section will focus will be derived from the leading treatises on this subject: ${ }^{37}$ I have no expertise on the positive law of marine salvage and no ability to assess whether the treatise-consensus I will report is accurate.

\footnotetext{
36 For some accounts of why I do not think that in the United States the internally-right answer to moral-rights-derived legalrights question (the kinds of questions with which I think parts of constitutional law, all of the common law, and non-statutory marinesalvage law are concerned) will not in general be the answer that would be allocatively efficient, see Markovits, op. cit. supra note 1 at 26-34 and 44-47 and Richard S. Markovits, Liberalism and Tort Law: On the Content and Economic Efficiency of a Liberal Common Law of Torts (unpublished article manuscript currently under submission, 2005).

37 See, e.g., David W. STEEl and Francis D. Rose, KenNedy's LAW Of Civil SALVAGE (5th ed., 1985); GeOFFrey Brice, Maritime Law of Salvage (1983); Martin J. Norris, Benedict on Admiralty, The LaW OF SAlvage (7th ed., 1983); and GRANT GILMORE AND CHARLES BLACK, THE LAW OF ADMIRALTY (henceforth GILMORE AND BLACK) (2nd ed., 1975).
} 
Third, it is clear that the positive judge-announced law of the United States on which this section will focus is different in some respects from the positive judge-announced marine-salvage law or actual "legal" practice of other countries. For example, American courts seem to be less willing than British courts to award compensation to pure-life salvors (to rescuers who save lives but no property) and to place a lower value on lives saved than do their British counterparts. ${ }^{38}$ American and British courts also seem to differ on the way to divide any compensation that is awarded marine salvors between owners of the salving ship on the one hand and its officers and crew on the other. ${ }^{39}$

Fourth, the fact that many marine-salvor-compensation cases are submitted to arbitration may not significantly undercut the significance of judge-announced marine-salvage law-in particular, will not do so if (as some observers claim) “[a]rbitrators generally calculate salvage awards using the same methods as do courts." 40

Fifth, the greatly-admired authors of at least one of the canonical treatises on admiralty law appear to disagree with the assumption this section makes that judicial marine-rescuee-to-rescuer-compensation practice can be derived from the holdings and dicta of the canonical cases in the field-indeed, manifest any consistency whatsoever. Thus, Grant Gilmore and Charles Black have argued that (1) "no formula precise enough to be useful can be worked out to indicate how large salvage awards will be in particular cases," 41 (2) "eventually the trial judge will pull an arbitrary number out of the air,"42 and (3) “each award continues to be a law unto itself." 43

Sixth and finally, my decision to ignore Gilmore and Black's skeptical conclusion and adopt the consensus treatise-writer position (which Landes and Posner and the author of the HARVARD Note also adopt)

"Historically, [in the United States,] the saving of life was regarded as fulfilling a moral duty but not as entitling the salvor to a reward." See GILMORE AND BLACK at 532. Since 1912, by statute, "salvors of human life, who have taken part in the services rendered on the occasion of the accident giving rise to the salvage, are entitled to a fair share of the sum awarded to the salvors of the vessel, her cargo, and accessories.” (See 37 STAT 242 [1912], 46 U.S.C.A. § 729.) At least one American court has held that this statute does not entitle pure-life salvors to compensation if no property is rescued at the time they saved the lives in question-e.g., even if the imperiled ship sinks and is raised subsequently. See In re St. Joseph-Chicago S.S. Co., 262 F. 535 (N.D. Ill. 1919). Other American courts have argued that life salvors are entitled to compensation only if they had to forego a meaningful opportunity to rescue non-life salvage to save the lives they rescued. See Strachan Shipping Co. v. Cities Services Refining Transport Co., 42 F.2d 524 (1930). In any event, even if the life salvor is held to be entitled to compensation under the statute, he is not entitled to recover from those he has saved: his share must come out of the award made against the property that has been salved. Moreover, in practice, life salvors have received a surprisingly low percentage of the awarded compensation. Although the few life-salvage cases on which the following assessment was based may have been atypical in that the life salvors faced substantially less danger and difficulty than the property salvors, one treatise concluded that "if the few life salvage awards that have been made are enough to support a generalization, it can be said that it is still far more profitable to save property than to save lives.” See GILMORE AND BLACK at 573. British courts can award compensation to pure-life salvors at the discretion of the Government, and, in practice, seem to grant purelife salvors awards more frequently do than their American counterparts and to place a higher value on lives saved than do their American counterparts. See HARVARD Note at 1898 n. 10 and D. Rhidian Thomas, Life Salvage in Anglo-American Law, 10 J. MAR. L. \& Сом 79, 90-91, 101 (1978).

39 GILMORE AND BLACK (published in 1975) reports (at 566) that in the "recent American cases the ordinary division is twothirds to the owner, one third to the crew" and cites a 1958 edition of Kennedy's treatise on civil salvage for the proposition that "the English courts were more favorable to the owners, a three-fourths to one-fourth split being customary.” See WiLLIAM R. KENNEDY, THE LAW OF CiviL SALVAGE (henceforth KenNEDY) (ed. by McGuffie) 235 (4th ed., 1958).

$40 \quad$ See HARVARD Note at 1897 n. 8, citing BRICE, op. cit. supra note 36 at 63.

41 See GILMORE AND BLACK at 564.

$42 \quad$ Id. at 563.

$43 \quad$ Id. 
has the virtue of being a decision against interest. The Gilmore and Black claim clearly disfavors the hypothesis that judge-announced marine-salvage law is allocatively efficient—a hypothesis that I am seeking to disprove.

After commenting on the third-best-allocative-efficiency of five components of "marine-peril law" other than the approach the courts have taken to calculating the compensation marine salvors are legally entitled to secure from their rescuees, this section will summarize and assess the third-best-allocative-efficiency of the way in which most treatises claim the courts calculate such marine-salvage awards.

The first component of marine-peril law whose TBLE I want to discuss that technically does not relate to the compensation that successful marine salvors are entitled to secure from rescuees when they have not negotiated a binding price for their services is the law on "finders" of property that is classified as "abandoned property” rather than salvage. ${ }^{44}$ The general American rule appears to be that finders of abandoned property have title to the property they have found. This majority rule contrasts with "the rule in England and in a minority of U.S. states...that abandoned property escheats to the state subject to a salvage claim by the finder." 45 The American majority rule will be allocatively inefficient if (1) the allocative transaction cost that would be generated by any escheat/state-granted-compensation-award proceeding minus (2) the allocative benefits the net fiscal gain to the State would generate by reducing the allocative transaction costs and allocative-efficiency losses the State generated in the course of financing its operations and/or by enabling the State to make other allocatively-efficient expenditures exceed (3) the amount by which the current American majority rule misallocates resources relative to its escheat/salvage-award alternative by inducing too many resources to be devoted to searching for sunken treasure from the perspective of allocative efficiency. The current American majority rule could have this last tendency for two reasons: primarily because each American hunter's efforts reduce the probability that other treasure hunters' efforts will be successful and possibly because various other Pareto imperfections deflate the private cost of hunting for sunken treasure.

The second issue of this type I want to discuss is the third-best-allocative-efficiency of the legal rule that those who attempt marine rescues have a legal entitlement to compensation from the potential rescuees whose lives or property they tried to rescue only if their rescue-attempt was successful. Landes and Posner argue that this rule seems likely to be third-best-allocatively-efficient for two reasons. First, because even when one takes into consideration the tendency of this rule to generate allocative transaction costs by making it necessary to adjudicate the issue "was a particular rescue-attempt successful,” the rule will tend to reduce the allocative

$44 \quad$ Apparently, in the technical legal sense, property is classified as "abandoned" when either

(1) the owner has relinquished the property voluntarily because its expected value to him has become zero or negative or

(2) the owner's identity has become so obscure by passage of time or other circumstances that the costs of ascertaining it would be prohibitive.

See Landes and Posner at 105.

$45 \quad$ Id. at 106. 
transaction costs generated by litigation (by reducing the number of claims that are brought). ${ }^{46}$ Second, because the rule will also tend to increase allocative efficiency by increasing the effort salvors make and the skill they manifest when devoting time to a rescue-attempt. ${ }^{47}$ In fact, the "no cure/no pay" rule will also tend to increase allocative efficiency in a third way: given that (1) (even with the information that potential rescuees will provide) triers-of-fact will often not be able to identify those unsuccessful rescue-attempts that were ex ante allocatively inefficient and (2) the awards that would be TBLE for courts to make to those who made unsuccessful marine-rescue attempts (if they did grant awards to such parties) would more than cover the variable cost of their unsuccessful rescue-attempt, the relevant legal rule will tend to increase allocative efficiency by deterring salvors from making rescue-attempts that were ex ante allocatively inefficient. All things considered, then, I suspect that the "no-cure/no-pay rule” is third-best-allocatively-efficient. ${ }^{48}$

The third non-C-formula component of marine-peril law whose allocative efficiency should be discussed is the law's failure to impose a duty on potential rescuers in any category to make rescue-attempts they should have perceived to be ex ante allocatively efficient. I will first analyze the third-best-allocative-efficiency of imposing a duty to make all rescue-attempts that the potential rescuer should have perceived to be ex ante allocatively efficient that is not combined with any program for rewarding those who make the rescueattempts - e.g., with any program of direct government awards, with any admiralty-law rule entitling marine rescuers to secure compensation from the rescuees, or with any law-of-restitution rule entitling marine rescuers

$46 \quad$ Id. at 104 and at 104 n. 18.

47 Id. at 104. Landes and Posner's articulation of this point is poor: "If payment were not conditional on success, the rescuer would have a greater incentive to reduce his effort and energy for a given quantity of rescue inputs." This formulation is deficient because, from the perspective of allocative efficiency, the amount of inputs a salvor devotes to a rescue-attempt (the allocative cost of that attempt) depends not just on the number of man-hours devoted to the attempt and the identity of the rescue-attempters but also on how hard they work at executing the rescue-attempt.

48 The HARVARD Note makes three counterarguments to this conclusion that I do not think can bear scrutiny. First, it argues that the relevant rule increases the allocative transaction costs that marine-peril-related litigation generates by making it necessary for triers-of-fact in successful-rescue cases of this kind to calculate what it refers to as "the risk premium" that must be paid to salvors "to compensate salvors fully for attempts that came to naught.” See HARVARD Note at 112 and 112 n.53. In fact, regardless of whether rewards are made only to successful salvors or to all actors who made marine-rescue attempts, the TBLE compensation-award formula would require relevant triers-of-fact to make such determinations- to discover inter alia the total amount of variable and fixed rescueattempt costs that were incurred by the members of the actual set of operating salvors and would be incurred by the members of the allocatively-efficient set of operating salvors as well as the amount of salvage these two sets of salvors would rescue and the environmental allocative losses these two sets of salvors would prevent or cause. Second, the HARVARD Note argues that the rule in question may misallocate resources by inducing potential marine rescuers to make rescue-attempts that are ex ante allocatively inefficient by inflating the private benefits of acts that increase the probability that they will be successful. Id. at 112 . In fact, although marine-salvage law may produce this effect, the component of the law that will do so is not the no-cure/no-pay rule but the fact that the ex ante weighted-average-expected or certainty-equivalent value of the actual and TBLE compensation-award is higher than the variable cost of any rescue-attempt that is made. Third, the HARVARD Note argues that the no-cure/no-pay rule tends to decrease allocative efficiency by deflating the ex ante profitability of rescue-attempts to casual salvors. Id. at 1912-13. In fact, although the rule does tend to deter risk-averse salvors of any type from making rescue-attempts by increasing the risk costs any such attempt would impose on them and may deter casual salvors more on this account than professional and semi-professional salvors (who have a larger portfolio of rescue-attempts and therefore have to incur lower risk costs to attempt any given rescue), that fact does not imply that the rule will misallocate resources on this account: risk costs are allocative costs and, ceteris paribus, if their presence critically affects the profitability of a rescue-attempt, it will critically affect the allocative efficiency of that rescue-attempt. Of course, ceteris paribus, the no-cure/no-pay rule may misallocate resources by increasing the sum of the risk costs borne by all parties it affects. However, there is no reason to assume that the rule will have such an effect: although it will increase the risk costs that rescue-attempters bear, it will simultaneously decrease the risk costs that potential rescuees bear (by eliminating the possibility that they will not only have to bear the marine loss that eventuated but also have to compensate rescue-attempters whose rescue-efforts failed). 
to secure compensation in "unjust enrichment" suits or in quantum meruit. In such a world, the imposition of such a duty to rescue would tend to increase allocative efficiency by decreasing the misallocation that potential rescuers generated by failing to make rescue-attempts they should have perceived to be ex ante allocatively efficient that they were in position to execute but would misallocate resources or generate allocative costs (1) by deterring allocatively-efficient investments in marine-salvage capacity by deflating the profits that the actors on whom this duty might fall could earn by putting themselves in a position to effectuate allocatively-efficient rescues (by investing in salvage ships, salvage equipment, salvage personnel, salvage-personnel training, and salvage-deployment), (2) by deflating the profitability to potential rescuees of the various types of marine-perilavoidance moves they could make, possibly (3) by inducing potential rescuers to make rescue-attempts that were ex ante allocatively inefficient when the product of (the probability that they would mistakenly be found liable for making the attempt in question) and (the penalty that would be imposed on them if they were found guilty or liable for failing to make the attempt in question) was higher than the private cost to them of making the relevant rescue-attempt, and (4) by generating various implementation allocative transaction costs and implementation-financing allocative costs. Although one therefore cannot determine the allocative efficiency of imposing a duty to rescue in the absence of any provision for rewarding those who make allocatively-efficient rescue-attempts, I would guess that in such a legal environment it would be allocatively efficient to impose such a duty. However, that conclusion (1) depends on certain pessimistic assumptions about potential salvors' willingness to make rescue-attempts that would not be profitable, (2) would be strengthened if, by performing an expressive function, the imposition of such a duty would increase the inclination of our society's members and participants to serve as Good Samaritans when it would be allocatively efficient for them to do so, (3) would be strongest when the potential rescuer was a casual salvor, intermediately strong when he was a semiprofessional salvor, and weakest when he was a professional salvor since the marine-salvage-investmentdecision misallocation that would be generated by the imposition of such a duty with no provision for compensation would be greatest when the potential rescuer was a professional marine salvor, etc. Indeed, for this reason, absent a provision for compensation, it might be third-best-allocatively-efficient to impose such a duty only on casual potential salvors or only on casual and semi-professional potential salvors.

Of course, in our actual world, a decision to impose such a duty to make ex ante allocatively-efficient rescue-attempts on actors who should know that they are in a position to make such rescue-attempts will be made in a legal environment in which successful marine salvors in the relevant category will normally be legally entitled to obtain compensation from the owners of the property and lives they rescued. In this legal environment, the imposition of such a duty to rescue should not cause salvage-operation-investment-decision misallocation or potential-rescuee avoidance-decision misallocation. Admittedly, in such a legal environment, the imposition of such a duty to rescue might cause misallocation by inducing potential salvors who fear that triers-of-fact may incorrectly find that a rescue-attempt option that they reject was allocatively efficient to make allocatively-inefficient rescue-attempts-in particular, will do so if the combination of the award for making a 
successful rescue-attempt and the penalty for failing to attempt the rescue in question critically inflate the profitability of making the rescue-attempt. However, I suspect that in such a legal environment the imposition of such a duty to rescue might well tend to increase allocative efficiency more by increasing the profitability of making allocatively-efficient rescue-attempts that admiralty law and practice would not otherwise have rendered profitable and by increasing the inclination of potential salvors to make such rescue-attempts even when they would not be profitable than it would decrease allocative efficiency by inducing potential salvors to make allocatively-inefficient rescue-attempts, by generating the allocative transaction costs of processing the State's civil and criminal claims against potential salvors who rejected rescue-opportunities, and by generating the allocative transaction costs and other sorts of allocative losses of financing the associated duty-creation and duty-enforcement activities.

The fourth non-C-formula component of marine-salvage law whose allocative efficiency should be discussed is the set of rules for dividing salvage-awards (1) between the owners of the salving ship on the one hand and her crew (master, officers, ordinary seamen) on the other and (2) among the individual officers and crew. At least five points or sets of related points are worth noting in this context.

First, the salvage-award division could affect at least three sets of marine-peril-related decisions and three related types of marine-peril-related misallocation: (1) decisions about whether to make a rescue-attempt and attempt/no-attempt misallocation, (2) decisions about the way in which any rescue-attempt that is actually made will be carried out and the misallocation generated by such choices, and (3) salvage-operation-investment decisions and misallocation.

Second, some of the effects of court-ordered award-divisions on the various types of choices and misallocations just listed will be substantially reduced by the impact that such divisions have on the conventional-wage terms to which the owner of the salvage ship and his crew (the officers and ordinary seamen who work on his ship) agree. Economic theory suggests that, ceteris paribus, if potential salvors and their employees believe that the employees or some subset of the employees will be given $\$ X$ in salvage-awards, the conventional wages paid to the salvor's employees or the relevant subset of those employees will be reduced by $\$ \mathrm{X}$ - that, ceteris paribus, the fact that salvor crews are given salvage-awards will not affect their total wagepackage, which will be determined by the supply of and demand for the type of labor they can perform. Of course, economic theory also reveals that the relevant ceteris are not all paribus. Thus, court-ordered awarddivisions will affect the total-wage-related risk costs that salvage-operation investors and the crews of ships that attempt marine rescues bear (an allocative-efficiency effect). Moreover, because the fact that court-ordered salvage-award divisions will affect other employment-contract terms will not eliminate their impact on the immediate rescue-related incentives of decisions of shipowners, officers, and crews (because the effect such court-decisions have on the short-run profits these parties can earn by making particular rescue-attempt decisions will not be completely offset by related changes in their future labor contracts), court-ordered salvageaward divisions will affect (1) the nature of the rescue-attempts that are made (both a positive economic and an 
economic-efficiency effect) by altering the incentives that crew members have to work harder and more skillfully when attempting marine rescues and to risk injury or death when making such attempts, and relatedly both (2) the number of rescue-attempts that given ships are used to execute and (3) the total amount of marinesalvage-operation investments that are made by altering the profits that a shipowner can earn by using his ship to rescue some or all of a given body of salvage (two positive effects that have allocative-efficiency consequences).

The third set of comments I want to make on the admiralty courts' award-division practices relate to their impact on rescue-attempt/no-rescue-attempt decisions and misallocation. Assuming that (1) admiralty-law award-divisions override any division specified in the labor contract between the salvage-ship owner and his employees $^{49}$ or that the applicable employment contracts do not cover this issue, (2) the decision whether to make a rescue-attempt is made by the shipowner or by someone whose choice is determined by the shipowner's interest, (3) the value the court attributes to salved property and lives equals their allocative value, (4) the rescue-attempt either will not affect the allocative environmental losses the marine peril generates or, if it does, the total award reflects any related allocative benefits the rescue-attempt generates and the shipowner is liable for any environmental losses the rescue-attempt generates and his liability is not externalized through insurance coverage or bankruptcy options, and (5) the private variable cost of the rescue-attempt equals its allocative counterpart, the law-specified division between owners and crew will eliminate attempt/no-attempt misallocation if the share of the award the law gives to the shipowner equals his share of the total private variable cost of the rescue-attempt ${ }^{50}$ to him and his ship's crew. Of course, if the preceding conditions are not

49 I have not been able to ascertain whether admiralty courts are willing to override the division of a salvage-award that is specified in an employment contract or collective-bargaining agreement between the owner of a salvage ship and its officers and crew. I have found no case directly on point, and the information I have gleaned from experts and from treatises favor different conclusions. On the one hand, labor-law experts assume that admiralty courts would not be willing to override employment contracts or $a$ fortiori collective-bargaining agreements because those agreements when made are supposed to comprehensively control employer-employee relations. This position is supported by the fact that, with the exception of one jurisdiction that has recently changed its mind, American jurisdictions have consistently held that collective-bargaining-agreement "maintenance and cure" (accommodation and medical-care) provisions trump the decisions that admiralty courts would make (when the injured crew-member can show that the actual hospital and medical fees he has to pay exceed the per diem sums specified in the collective-bargaining agreement). For the majority American position, see Baldassaro v. United States, 64 F.3d 206 (5th Cir. 1995). For the deviant Third Circuit position, see Barnes v. Andover Company, L.P., 900 F.2d 630 (3rd Cir. 1990). For the recent decision overruling the traditional, deviant Third Circuit position, see - On the other hand, wages-and-hours legislation and safety legislation does sometimes override the terms of collective-bargaining agreements, admiralty-law experts tell me that the disposition of admiralty-court judges to secure the interests of seamen (see also GILMORE AND BLACK at 567) would incline them to conclude that judicial awards that exceed the sum to which their employment contract would entirely then override the employment contract, and as Gilmore and Black point out (id.) a relevant statutory provision- “every stipulation by which any seaman consents...to abandon any right which he may have or obtain in the nature of salvage shall be wholly inoperative” (46 U.S.C.A. §100) — entitles crew to the award a court would give them when it exceeds the compensation to which their employment contract entitle them or to which they agree post-rescue.

The shipowner's share of these costs will depend on the percentage of these costs constituted by

(1) the weighted-average ship-and-equipment costs the rescue-attempt should be expected to generate (by wearing out these assets, by damaging them, or by causing them to be lost);

(2) the opportunity cost of diverting these assets to the rescue-attempt in question (the alternative activities [including speedier delivery] in which the ship could have engaged had it not been used to execute the rescue-attempt) that the shipowner would bear because the rescue-attempt prevented him from supplying the towing services his ship could otherwise have supplied or because he was obligated to compensate the owners of the cargo he was carrying and his passengers for the costs any related delay in their arrival at their destination imposed on them (and he was not 
fulfilled, the conclusion in question will not be correct (unless the various departures from the conditions in question fortuitously cancel each other out in relation to this issue). Thus, if the total salvage-award is lower than the allocative value of the property and lives saved and environmental damages prevented and/or the private total variable cost of the rescue-attempt is higher than its allocative counterpart (with the relevant percentage distortion being the same for the private variable costs incurred by the shipowner and the ship's crew), the share of the award that the shipowner will have to be given for the profitability of the rescue-attempt to him to be undistorted will be higher than the share he would bear of the total private variable cost of the rescue-attempt. In the other direction, if the total salvage-award is higher than the allocative value of the property and lives saved and environmental allocative losses prevented ${ }^{51}$ and/or the private variable cost of the rescue to the shipowner is lower than its allocative counterpart, the share of the award the shipowner will have to be given for the profitability of the rescue-attempt to him to be undistorted will be lower than the share he would bear of the total private variable cost of the rescue-attempt.

According to Gilmore and Black, in the United States, the ordinary admiralty-law division between shipowner and crew circa 1975 was two-thirds to the shipowner and one-third to the ship’s crew. ${ }^{52}$ According to Kennedy, ${ }^{53}$ whom Gilmore and Black cite on this point, ${ }^{54}$ since late in the nineteenth century, in England, “ordinary apportionment” has been three-fourths to the owner and one-fourth to the crew.

I simply do not have the data needed to determine whether either of these divisions would eliminate rescue-attempt/no-rescue-attempt-decision misallocation. Since there is no reason to believe that the relevant facts differ appropriately in the two countries, it is less likely that both countries' award-division practices eliminate such misallocation than that either country’s practices do so.

The fourth set of comments I wish to make about the admiralty courts' award-division practices relate to their impact on rescue-attempt-quality-decisions and misallocation. Assuming that (1) the admiralty-law division of the total salvage award controls, (2) the private cost to individual salvage-ship crew-members of working harder, working more carefully of skillfully, or taking a greater risk of being injured or killed equals its

insured for this contingency) or would lose profits in the future because the delays that resulted from the rescueattempt damaged his reputation for reliability;

the weighted-average costs the rescue-attempt should be expected to generate by causing cargo (passengers) to be damaged (injured or inconvenienced) or lost (killed) for which he was liable and not insured or judgment-proof (or whose generation would cost him future profits by damaging his reputation); and

the weighted-average-expected costs the rescue-attempt would impose on his ship's officers and crew by making their labor more costly to them (injury and death aside) or by injuring and killing them to the extent that he was liable for these costs and not insured or judgment-proof for them or to the extent that the generation of these costs would increase his future costs by raising the wages he had to pay personnel or the insurance premiums he had to pay.

51 Since the private value of property to its owners may exceed its allocative value, the possibility to which the text refers is not ruled out by the admiralty-law rule that salvage awards for rescued property cannot exceed the value of the property to its owner(s).

52 Id. at 566, citing various treatises and cases at $566 \mathrm{n}$. 102. Colleagues who are experts in admiralty law and practice have told me that in their view, these numbers also reflect current judicial practice. Gilmore and Black indicate as well that "if a few salvage arbitrations reported in American Maritime cases are representative, the arbitrators tend to give a larger proportion of the award to the owners than do the courts.” Id.

$53 \quad$ KENNEDY at 235.

$54 \quad$ GILMORE AND BLACK at 567. 
allocative counterpart, and (3) the relevant individual officers and ordinary seamen would not have to pay any taxes on the awards they received, the division of the award between shipowners and personnel and among personnel will reduce the salvage-ship’s individual officers and ordinary seamen to make allocatively-efficient decisions as to how hard and skillfully to work and what risks to take when carrying out a rescue-attempt if they result not only in the total award to the ship’s crew's increasing dollar for dollar with their allocative product but also in each individual actor's award’s increasing dollar for dollar with the amount by which his efforts increased the allocative value of the property and lives that were saved and the environmental damage that was prevented. Unfortunately, from the perspective of this section's organization, this conclusion implies that I cannot discuss the impact of the division of the award on the allocative efficiency of the ship's personnel's laboring decisions without taking account of the size of the total award made to the ship's owner and crew combined since that total will affect the total reward received by all crew-members combined and by each individual officer and ordinary seaman. In any event, the preceding conclusion implies that, to the extent that the private cost to each relevant crew-member of being injured or killed is lower than the allocative cost (because [1] he does not fully internalize the non-material loss his friends and family suffer when he is injured or killed, [2] the associated medical expenses are subsidized by insurance-payments or government-transfers, [3] the non-wage costs of his being disabled are partially offset by private and government disability insurance, unemployment insurance, and welfare-transfers, and [4] the wage cost of his being disabled or killed is deflated by the taxes he would have paid on the gross income he lost ${ }^{55}$ and/or various other Pareto imperfections that caused his gross wage to be lower than his allocative product), the award that a crew-member must expect to be given for his effort and risk-taking incentives to be undistorted will increase with his effort and risk-taking by less than his extra effort and risk-taking increase his contribution to the allocative value of the property and lives saved and environmental damage prevented. The preceding analysis also implies that, to the extent that the private cost to the actor of being injured or killed is higher than the allocative cost (because the relevant Pareto imperfections inflate the wages his injury or death prevent him from causing) and to the extent that taxes reduce the after-tax award he receives below the gross sum he is awarded, the gross award the relevant individual officers and ordinary seamen would have to anticipate securing for their effort and risk-taking incentives to be undistorted would have to increase with increases in their efforts and risk-taking by more than such increased efforts and risk-taking increased the allocative benefits their rescue-attempt labor generated.

This discussion should provide a basis for assessing the impact of the way in which marine-salvage law divides the total compensation it awards between salvage-ship owners and crew and among salvage-ship crewmembers on the amount of misallocation salvage-ship officers and ordinary seamen generate because of the

$55 \quad$ Such awards are taxable earned income. However, it is possible that in practice salvor officers and crew members prevent their awards from being taxed (almost certainly fraudulently) by setting up foreign (say, Cayman Island) corporations for which they nominally work and arranging for any salvage-awards they secure to be paid to those corporations. I have no empirical information about the extent to which salvage-ship personnel engage in such behavior or the likelihood that they would believe at the time of the rescue-attempt that their efforts to escape taxation in this way would be successful. 
way in which they design or execute any rescue-attempt that is made. Because admiralty-law experts have told me that Gilmore and Black’s account of the relevant positive law was very accurate when written in 1975 and has become more accurate since then as courts have self-consciously chosen to conform their decisions to the Gilmore and Black account of judicial practice, I will assume that Gilmore and Black's description of the living law is correct.

Three aspects of the Gilmore and Black description of the courts' award-practices are relevant in the current context. First, Gilmore and Black state that the total award made to a salving ship's owner and crew combined is directly related to the value of the property and lives saved, the promptness of the rescue-attempt, and the skill and bravery that the rescue-personnel showed but is inversely related to the damage the rescueattempt caused negligently and the amount by which the rescue-attempt reduced the (private) cost-effectiveness of the rescue-attempts of others by unnecessarily interfering with them. ${ }^{56}$ Although from the perspective of allocative efficiency this practice involves a kind of double-counting (in that speed, skill, and bravery increase the award both directly and indirectly by increasing the value of property and lives saved), it does suggest that the total award to shipowner and crew combined, hence the award to the ship's crew as a group, and hence the award to individual ship officers and ordinary seamen do vary in the allocatively-efficient direction with the allocative efficiency of each individual crew-member's conduct. Two additional points are relevant at this juncture. First, the preceding account provides no basis for concluding that-even if it would be accurate to assume that individual crew members would make the laboring choices that would maximize the equivalentdollar interest of the owner and crew of the ship combined-the quantitative relationship between the total sum awarded and the allocative product of the choices the ship's crew made would eliminate any distortion in each individual crew-member's work incentives. Second, bravery and courage and hence rewarding bravery and courage may be more allocatively efficient than one might suppose. Although in our society potential rescuers do not have a moral (or legal) obligation to make choices that would subject them to a significant risk of death or substantial bodily injury, that fact does not reflect a judgment that choices to incur such risks would be allocatively inefficient. Bravery is often allocatively efficient. Moreover, to the extent that that the private cost of bravery is deflated less by private insurance and government transfers than the private value of any awards paid for bravery is deflated by taxation, it may be allocatively efficient to make the given award for brave conduct exceed that conduct's allocative product.

The second component of Gilmore and Black's account of salvage-award practice that is relevant in the current context is their more refined description of the factors that influence the percentage of the total award made to the owner and crew of a ship that has made a successful marine-rescue attempt that is allocated to the crew:

In high order salvage, where the individual salvors, under dangerous conditions, show skill, resourcefulness, and courage, the crew’s share will be upped. In low order salvage, which is just enough 
more than simple towage to qualify at all and where the crew has done little, the owner will get a larger than usual share. ${ }^{57}$

Once more, this implies that admiralty-law practice will tend to decrease rescue-attempt-quality misallocation by making the awards to individual actors increase with the allocative product of their conduct. Obviously, unless the awards are properly individuated, an individual's choice that would increase his allocative product by \$X would not increase his individual award by \$X even if it would increase by $\$ X$ the award his ship’s officers and ordinary seamen combined obtained. ${ }^{58}$

The third component of Gilmore and Black's account of salvage-award practice that is relevant in the current context relates to the individuation of salvor-crew awards. I will initially assume that all awardindividuation is done by the courts. I will then discuss the significance of the fact reported to me by experts that ship masters often control the awards that their ship’s individual officers and ordinary seamen receive.

Gilmore and Black offer the following description of admiralty-court award-individuation:

"Basic" awards to the crew are usually made according to rank or monthly pay; the master and senior officers receive substantially more than ordinary seamen. These awards are made to all crewmembers of the salving ship, whether or not they personally took part in the rescue work. Additional awards are then frequently made to individuals who played conspicuous roles: to those who boarded a derelict ship, helped to extinguish fires, or navigated her to port. Ingenuity as well as personal bravery may justify an additional award, as in the case of an officer who by noticing that, contrary to the charts, tides were higher at night than during the day, contributed the idea that made it possible to refloat a stranded ship after several daytime attempts had failed. ${ }^{59}$

I have three comments to make about the impact of such an individuation scheme on rescue-attempt-quality misallocation. First, if the total award to the crew equaled the crew's allocative product, the practice of giving non-participants the "basic" award would be misallocative even if across all of a ship's rescues the practice had no impact on individual crew-members' compensation-shares. At least, this conclusion will be justified unless each choice of each individual crew-member was motivated by a desire to maximize the equivalent-dollar gain to the crew as a whole rather than to the individual crew-member. Second, if contrary to my expectation the differences in the basic salvage awards that the individual members of different categories of salvage-ship crew receive do affect their relative total compensation, I would be unable to judge whether the practice of giving substantially higher "basic" awards to individual officers than to individual seamen would be allocatively efficient-i.e., would induce shipowners to hire an allocatively-efficient combination of officers and ordinary seamen. More specifically, on the above assumption, this practice would be allocatively efficient if and only if the basic-award difference was the difference in the ordinary allocative products of individual workers in the

$57 \quad$ Id. at 566.

58 Admittedly, the tendency of any such disparity to cause misallocative laboring choices to be made will be smaller to the extent that (1) individual officers and crew-members are motivated by the equivalent-dollar interest of the ship-personnel group as a whole and/or (2) the decision of a given officer or crew-member to act allocatively efficiently encourages other ship personnel to make allocatively-efficient choices (that would not be individually profitable for them but for their tendency to encourage others to make such choices).

$59 \quad$ Id. at 567. 
two categories. However, if, as I suspect, differences in the weighted-average amounts of salvage awards that a ship’s average officer and average seamen will expect to obtain do not affect differences in their total weightedaverage-expected wage-packages, this component of the courts' award-division practice will affect allocative efficiency only by changing the amount of “total-wage-package” risk costs the ship's crew-members bear. Third, the reported “additional award” practices of the courts all individuate individual crew-members' awards in the direction that would be allocatively efficient, though I do not have the data necessary to assess whether the magnitude of the individual "additional awards" that are given is allocatively efficient.

I now want to make four comments on the likely allocative efficiency of any award-individuation executed by salvage-ship masters or captains. First, if, as I expect, the owner of the salvage ship and the crew know that the crew will obtain master-awarded compensation, the conventional-wage component of the crew's compensation will be adjusted to reflect that fact and the impact of the master-made awards on anything of interest will be substantially diminished. Second, for the same reasons that the following conclusion applied to court-made awards to crew-members, the interdependence of salvage-award payments to crew-members and the conventional wages they receive will not totally eliminate the positive-economic effects or allocative-efficiency effects of the master-made awards. Third, if ship-masters seek to individuate salvage awards in the way that would promote the shipowner's interest (because they feel obligated to do so and/or because they realize that it is in their long-run career interests to do so), they will individuate the relevant awards in the way that is most allocatively efficient if (1) the law eliminates any distortion in the profits the salvage-ship owner makes or (2) any distortion in the profits of the marine-salvage business that the law does not eliminate does not critically affect the profitability of the most profitable individuation scheme (relative to some less profitable alternative). Although the first of these two conditions is unlikely to be fulfilled, I see no reason to believe that the second is not fulfilled. Fourth, the probability that the master will divide crew salvage-awards in the way that is in his employer's interest as opposed to doing so in some way that in his own short-run interest will be highest if he is the master of a salvage ship, next-highest if he is the master of a tugboat that is somewhat adapted to perform salvage operations, and lowest if he is the captain of a non-salvage passenger ship or freighter. This contestable conclusion rests on the assumption that, although employers always want to hire executives who make choices that are in the employer's interest, they will be less likely to investigate and be less likely to be disturbed by one-off choices or resolutions of issues that do not often arise than recurrent choices that play a significant role in the profit-performance of their business.

The fifth and final set of comments I want to make about admiralty law's award-division practices relate to their impact on salvage-investment decisions and salvage-investment misallocation. Four comments are in order. First, once more, the net effect of any such divisions the courts make on the profitability of salvage operations and hence salvage-operation investments will be substantially reduced by their impact on the conventional wages that ship officers and ordinary seamen are paid. Second, once more again, such awarddivisions can increase or decrease the profits that a salvage-operation investment will generate by changing risk 
costs and altering individual-rescue-attempt quality and profitability. Third, to the extent that such divisions increase or decrease individual-rescue-attempt profitability, they will tend to increase or decrease salvageoperation investment. Fourth, although this point would have to be qualified in a large number of ways that should by now be obvious, any such award-division's impact on the quantity of marine-salvage-operation investment is not likely to affect the misallocation that such investment-decisions generate because the change in investment-profitability is caused by effects that simultaneously change the allocative efficiency of marinesalvage investments in the same direction and presumptively to the same or a similar extent.

The final non-C-award component of marine-salvage law on which I wish to comment is its rule for dividing any marine-peril-related loss among the owners of the property and lives that were imperiled. The applicable current doctrine requires those owners of imperiled property to make those ex post payments to each other that would equalize the proportion of the value of the property that was imperiled that each ends up losing-i.e., that equalize among owners of imperiled property the ratio of (the sum of the private value of the property each lost and the positive or negative payments he made) to (the private value to him of the property that was originally imperiled). I want to make four comments about this doctrine. First, it should be emphasized that the doctrine in question (the so-called "general-average principle”) does not require payments to be made to or by potential victims whose lives were at risk but who owned no imperiled property and excludes from consideration the value of lives originally imperiled and lives lost when calculating the crosspayments that owners of imperiled property have to make to each other. Second, relatedly, and obviously, to the extent that (1) decisions about the focus of rescue-attempts (whether they are directed at saving lives or saving property) are controlled by the shipowner or by someone who is guided by the shipowner's interest, (2) the shipowner will not have to bear the cost of lives lost (is not formally liable for such losses or is insured or judgment-proof against having to pay damages for such losses), and (3) the salvor's monetary incentives (the Caward formula) and personal non-monetary preferences will not induce him to take all allocatively-efficient steps to rescue any imperiled lives, this exclusion of the private value of the lives that were imperiled and the private value of the lives that were lost from the victim- cross-payment calculation will misallocate resources by causing too few resources to be allocated to saving lives and too many to saving property for any given rescueattempt expenditure. Third, if (1) the general-average principle were applied accurately, either (2)(A) the private value of all pieces of relevant imperiled property and the private cost of salving all categories of imperiled property were either undistorted or distorted in the same direction by the same percentage or (B) the private value of different categories of imperiled property were distorted in different directions and/or by different percentages, the private cost of rescuing different categories of imperiled property were distorted in different directions and/or by different percentages, but either the sign and magnitude of the distortion in the private value of each category of imperiled property equaled the sign and magnitude of the distortion in the private cost of rescuing that category of imperiled property or the following ratio were the same for each category of imperiled property - the ratio of (the distortion in the private value of the property in question minus 
the distortion in the private cost of rescuing the property in question) to (the private cost of rescuing the property in question), and (3) both the shipowner's decisionmaker and the salvor made no relevant mistakes, the implementation of the general-average principle would prevent the misallocation that the shipowner might otherwise find profitable to generate by accepting offers of rescue-attempt variants whose attractiveness to him critically depended on his placing a higher value on saving a dollar of his own property or other property for whose loss he would personally have to pay than on saving a dollar's worth of someone else's property for whose loss he would not have to pay.

Fourth, although the conditions listed in the immediately-preceding sentence may not be fulfilled, with one important exception that will be explored immediately below, it would almost certainly be third-bestallocatively-efficient to proceed on the assumption that the conditions in question were fulfilled. I should add that the exception in question does not undermine the conclusion that-if the general-average principle were altered to take the value of imperiled and lost lives into account in an accurate way-its implementation would prevent the misallocation that would otherwise result from shipowners' favoring rescue-attempts that, from the perspective of allocative efficiency, were “biased” toward saving the shipowner's property and property whose losers the shipowner would personally have to compensate.

Fifth, there is some reason to believe that the actual implementation of the general-average principle causes exactly the opposite kind of rescue-attempt-type misallocation to the one with which the preceding two comments were concerned-viz., causes the shipowner to accept offers of rescue-attempt variants that are less allocatively efficient than available variants that would have been more likely to prevent damage to his own property. For this outcome to be generated, the following conditions must be fulfilled: (1) the combination of the damage to the shipowner's property that a particular rescue-attempt could prevent and the repair that that damage would occasion would increase the value of the shipowner's property, (2) either in theory or in practice the admiralty courts' general-average calculations ignore or undervalue the shipowner's gain, and (3) in part because the shipowner will not be charged for that gain, the amount of the related repair costs the shipowner would bear (because on their account he would have to make higher transfer-payments to other victims or would receive lower transfer-payments from other victims) is lower than the amount by which the preventabledamage/repair combination would increase the value of his property. The first two of these conditions require some elucidation.

I begin with the first. Even if one excludes the possibility that the shipowner may succeed in attributing to the perilous event pre-existing damage with which it had absolutely nothing to do if he succeeds in deterring a rescue-attempt that would have prevented that type of damage had it not already been present, the preventable-damage/repair combination can increase the value of the shipowner's property or his profits (transfer-payment consequences aside) in three sets of circumstances: (1) when the damage exacerbates a condition the shipowner would have had repaired in any event and the additional damage the peril inflicts does not reduce the value of his repaired property by as much as the cost he would otherwise have incurred to repair 
the pre-existing damage or (2) when, regardless of whether the preventable damage would have affected something that was already damaged or worn out, the repaired property would be superior to the pre-peril property. The second condition is that in practice and perhaps even in theory the general-average principle will not charge the shipowner for any gain the preventable-damage/repair combination in question would confer on him (salvage-law-required transfer-payment consequences aside). Although the experts with whom I have discussed this issue agree that, in principle, shipowners should be charged with any such gains they secure, they are not sure whether admiralty-law judges would take these gains into account if they knew that they had been generated and are certain that in many instances the other marine-peril victims will not be able to prove that the shipowner had secured such gains. In part, the latter conclusion reflects the objective difficulty of establishing the pre-existing condition and comparing the value of the repaired property with that of undamaged, unrepaired property. But in part, it reflects an institutional feature of salvage-law practice: judges rely on shipownerselected adjustors for estimates of the value of the property that was imperiled, the value of the property that was lost, the extent of any unrepaired or unrepairable damage that was done, and the extent to which the value of the property that was repaired was lower or, presumably, higher than the value it had prior to being damaged in the incident that gave rise to the litigation. Although the shipowners' adjustor-choices are constrained by requirements that they pick someone from a list of qualified adjustors, I am sufficiently cynical to believe that shipowners will be able to select adjustors who will not tell the court that the repaired property had pre-existing damage or wear (e.g., that the new hull was thicker than the worn-down hull that was damaged in the incident in question) or will underestimate the repair-costs the shipowner would have had to incur in any event or the amount by which the value of the repaired property exceeded the pre-incident value of the property in question.

Sixth and finally, although I am fairly certain that it is not third-best-allocatively-efficient for courts to rely on shipowner-selected adjustors in marine-salvage cases, I do suspect that if the courts in question selected such adjustors themselves using criteria that reduced the probability that the adjustors selected would have an incentive to favor the shipowners and were more cognizant of the possibility that shipowners might have, from the perspective of allocative efficiency, a bias against rescue-attempts that might prevent certain types of damage to their property, a version of the general-average principle that applied to potential victims whose lives had been endangered but who had no imperiled property and took account of the value of lives imperiled and lost when calculating the transfer-payments that all potential victims had to make or were entitled to receive would be third-best-allocatively-efficient.

I will now analyze the second-best and third-best allocative efficiency of the approach the courts have taken to figuring out how to determine the total award to make in any marine-salvage case and the second-best and third-best allocative efficiency of the protocol they use for this purpose. ${ }^{60}$ I start with the approach.

60 To ease the exposition, I will assume that either (1) the awards actually made are divided in an allocatively-efficient manner among the payees and payors-i.e., among rescue-ship on the payor side owners, individual officers, and individual ordinary seamen on the payee side and among owners of imperiled ships, owners of imperiled cargo, and owners of imperiled lives on the payor side- 
To my knowledge, no salvage-award court has ever said that its total-award decision ${ }^{61}$ was designed to minimize allocative inefficiency. ${ }^{62}$ Admittedly, such courts have sometimes explained their decisions in terms of consequences whose effectuation might be associated with increases in allocative efficiency. However, the correlation in question is far from clear and the judges seem to value the consequences to which they refer for reasons other than their connection to allocative efficiency. Thus, when courts justify their salvage awards by citing their tendency to encourage maritime commerce by reducing its hazards, ${ }^{63}$ it is not clear that they have “increasing allocative efficiency by encouraging maritime commerce” in mind. When courts justify their marine-salvage awards on the ground that they reward good Samaritans, ${ }^{64}$ it is not clear that the judges want to encourage Good Samaritanism if and only if it is allocatively efficient: to the contrary, they seem to be motivated by a distributional "preference” for rewarding Good Samaritans regardless of whether the Good Samaritan conduct in the instant case was allocatively efficient. In fact, even when the courts in question make reference to "goals" whose attainment seems likely to be allocative efficient, other things being equal—e.g., preventing unjust enrichment, ${ }^{65}$ deterring the theft of unguarded property, ${ }^{66}$ and preventing "the waste" that bilateral monopoly may cause in rescue situations in which time is of the essence, ${ }^{67}$ the judges' interest seems to be in the distributional desirability of securing these results (e.g., of preventing “exploitation” in bilateralmonopoly situations) rather than in the allocative efficiency of doing so.

Of course, for some purposes including those of Landes and Posner, the important question is not why judges resolve issues allocatively efficiently (if they do) but whether they resolve cases allocatively efficiently. For these purposes, the critical issue is whether the marine-salvage awards the courts have made are (third-best) allocatively efficient — whether the protocol the courts have used for this purpose is the third-best-allocativelyefficient protocol they could have followed.

The analysis that follows ignores the very real possibility that, despite the courts' and many legal scholars' claims to the contrary, not only are court-ordered marine-salvage awards not controlled by any

or (2) that any allocative inefficiency generated by the divisions in question will not affect the approach to calculating the total award or the magnitude of the total award in individual cases that is allocatively efficient. Both these assumptions are unrealistic.

61 Or its decisions about the way in which award-payments should be divided among payors on the one hand and payees on the other.

62 I take no position in this Article on whether the judicial resolution of various award-issues that would be most allocatively efficient would be the resolution required by our relevant moral-rights commitments, would be legally correct, or would be most desirable, rights-considerations aside. For accounts of these issues and a discussion of the relationship between the allocative efficiency of a choice and its justness, legality, and desirability (rights and legal considerations aside), see Markovits, op. cit. supra note 1 .

63 See, e.g., Mason v. The Blaireau, 6 U.S. (2 Cranch) 240, 266 (1804); B.V. Bureau Wijsmuller v. United States, 702 F.2d 333, 337-38 (2d Cir. 1983); Seven Coal Barges, 21 F. Cas. 1096, 1097 (C.C.D. Ind. 1870) (no. 12, 677); and The Charles Henry, S.F. Cas. 509, 510 (E.D.N.Y. 1865) (No. 2617). This string cite is taken from HARVARD Note at 1898 n. 13.

$64 \quad$ See, e.g., The Henry Ewbank, 11 F. Cas. 1166, 1170 (C.C.D. Mass. 1833) (No. 6376). This citation is also taken from HARVARD Note, this time at 1898 n. 16.

$65 \quad$ See, e.g., The Sabine, 1010 U.S. 384, 384 (1880), cited in HARVARD Note at 1898 n. 14.

$66 \quad$ See, e.g., The Clarita and the Clara, 90 U.S. (23 Wall.) 1, 17 (1874) and The Blackwall, 77 U.S. (10 Wall.) 1, 14 (1879), cited in HARVARD Note at 1898 n. 15.

67 See, e.g., Higgins, Inc. v. The Tri-State, 99 F. Supp. 694, 698-99 (S.D. Fla. 1951) and Magnolia Petroleum Co. v. National Oil Trans. Co., 281 F. 336, 339-41 (S.D. Tex. 1922), cited in HARVARD Note at 1898 n. 17. 
formula or protocol, they are not even guided in any coherent way by the factors the courts claim determine their award-decisions. In other words, this section assumes that Gilmore and Black are wrong when they conclude that trial judges set marine-salvage awards by "pull[ing] an arbitrary figure out of the air.”68 More specifically, the analysis' assumptions about the content of the positive law of marine salvage are based on the account of the 1958 Kennedy treatise on THE LAW OF Civil SALVAGE. ${ }^{69}$ I have made this choice for three reasons: (1) because experts I have consulted think that this treatise was accurate at the time it was written, most importantly (2) because Landes and Posner relied on this treatise ${ }^{70}$ and I want to criticize the argument they made for the allocative efficiency of the positive law as they saw it, and (3) because many experts have told me that with some exceptions that are easy to take account of-e.g., the fact that, today, salvors are far more likely to be liable for the environmental damage they do than they were in $1958^{71}$ — the Kennedy-treatise account continues to reflect reality.

According to the 1958 Kennedy treatise, courts determine the compensation they award in marinesalvage cases by considering the following factors:

A. As regards the salved property:

(1) the degree of danger, if any, to human life;

(2) the degree of danger to the property; and

(3) the value of the property salved.

B. As regards the salvors:

(1) the degree of danger to human life;

(2) the salvors' (a) classification [i.e., in my terms--professional, semi-professional, casual], (b) skill and (c) conduct;

(3) the degree of danger, if any, to property employed in the salvage service and its value;

(4) the (a) time occupied and (b) work done in the performance of the salvage service;

(5) responsibilities incurred in the performance of the salvage service-e.g., such as the risk that one might incur liability to passengers or shippers through deviation or delay; and

(6) losses or expense incurred in the performance of the salvage services-e.g., losses of profitable trade, expenses to repair damage to the ship or its gear, the cost of fuel consumed.

This basic account needs to be supplemented in at least eight ways.

First, at least in the United States, awards are not given to so-called "pure life” salvors-i.e., to salvors who have rescued lives but no property. Second, the value attributed to lives saved and injuries sustained is far lower than their allocative value. Third, although item B(2)(c)—salvor conduct—does cover individual-salvor decisions to execute a rescue-attempt variant that unjustifiably (allocatively inefficiently?) interferes more with the success of other rescue-attempts than an alternative rescue-attempt variant he could have executed would have done, item $\mathrm{B}(2)(\mathrm{c})$ appears not to cover the possibility that, from the perspective of allocative efficiency, too many rescue-attempts were made in the case in question —-though, as the next comment indicates, the courts

See GILMORE AND BLACK at 563.

See KENNEDY at 174.

See Landes and Posner at 101-02.

See Brough. 
may take account of this possibility when adjusting the award they make in response to their calculation of items $A(1)$ and $A(2)$ in the above list. Fourth, there is some reason to believe that courts define factors $A(1)$ and $\mathrm{A}(2)$ in the above list - the degree of danger to life and property - to take into consideration not only the probability that the salvage in question would be "saved” by Mother Nature or by the "self-rescue” efforts of the imperiled ship if no-one else made a rescue-attempt but also the probability that the salvage would have been rescued by another salvor had the successful salvor in question not made a rescue-attempt. Although, as we shall see, such a practice would have problematic effects on marine-salvage-operation-investment decisions, it would make the award a successful salvor receive depend on whether the full set of rescue-attempts to which his effort belonged was allocatively efficient. Fifth, although item $\mathrm{B}(2)(\mathrm{a})$ - the type of salvor involved in a particular case-does suggest that the courts take account of differences in the amount of fixed costs of salving that different types of salvors have incurred-and other items in the list-all items in set B other than item $\mathrm{B}(2)(\mathrm{a})$ - suggest that the courts take account of the variable cost of successful rescue-attempts, nothing in the list suggests that the courts take account of the other facts that will influence the ratio of the successful salvor's salvage-operation investment to his total variable cost of salving or the percentage by which the awards he receives when his rescue-attempts are successful must exceed the variable cost he incurred to execute his successful rescue-attempts for him to cover his salvage-operation fixed costs—viz., (if the calculation is made on a ship-by-ship basis) the number of rescue-attempts he will use the ship in question to make and the percentage of those rescue-attempts that will be successful. Sixth, just as nothing in the list suggests that the courts take account of the allocative efficiency of the number of rescue-attempts that were made on the salvage involved in the case at hand, nothing in the list suggests that the courts consider whether the current level of salvage-operation investment is allocatively efficient. ${ }^{72}$ Seventh, the list of salvor-attributes the courts consider does not contain the value of any cargo the salvor ship was carrying and the probability that it would be lost or damaged to any given extent-factors that will influence the allocative variable cost of the rescue-attempt and its private variable cost (to the extent that the salvor owns the cargo, will personally have to compensate its owner for any cargo that is lost or damaged, or will have to pay higher insurance premiums or incur other “costs" if he goes bankrupt because of his inability to compensate owners of lost or damaged cargo to whom he was liable). ${ }^{73}$ Eighth, as another leading treatise on marine salvage recognized, in practice, the factors under heading A are by far the most important determinants of the awards that are made, and "the time and labor expended by the salvors in rendering the salvage service"-factor $\mathrm{B}(4)$ —and "the value of the property employed in rendering the service and the danger to which such property was exposed"-factor B(3)—are the least important. ${ }^{74}$

72 These two omissions parallel the court's failure to assess for negligence a business' decision to stay in business at all or to produce the amount of output it chose to produce-i.e., to review for negligence an injurer's activity-level choices.

73 The author of the HARVARD Note pointed out this deficiency of current law (from the perspective of allocative efficiency). See HARVARD Note at 1915.

$74 \quad$ See Martin J. Norris, The LaW OF SALVAge 21-33 (1958). 
I will now analyze the second-best and third-best allocative efficiency of the approach the courts have taken to determining the protocol they should use to calculate the total award to make to individual successful marine salvors and the protocol they are reported to have followed when making such decisions in individual cases. My initial comments will assume that the courts could execute or commission all relevant theoretical and empirical analyses perfectly and costlessly. I will then consider the possibility that, although the above approach and protocol would clearly be allocatively inefficient if the above second-best-allocative-efficiencyanalysis assumptions were accurate, they might be third-best-allocatively-efficient, given the inevitable cost and probable inaccuracy of the theoretical and empirical work the court could do or contract out.

On second-best-allocative-efficiency-analysis assumptions, the approach courts have taken to determining the protocol they should use to calculate marine-salvage awards and the protocol they are reported to have followed to calculate awards in individual cases would be allocatively inefficient for at least eleven categories of reasons. First, although the courts never discussed the way in which they chose the protocol to follow when calculating marine-salvage awards, nothing suggests that they proceeded in either of the ways in which I have argued it would be second-best-allocatively-efficient to approach this issue:

(1) by listing the various types of allocative costs marine peril can generate, delineating the various ways in which marine-salvage awards can affect each of these types of allocative costs, determining the magnitude of each such type of cost that would result if any given marinesalvage-award protocol were followed, and identifying the protocol whose use would minimize the sum of such costs or

(2) by listing the various types of marine-peril-related misallocation that can be generated, delineating the various ways in which marine-salvage awards can affect the amount of each such type of misallocation that is generated, determining the magnitude of each such type of misallocation that would be generated if any given such protocol were followed, and identifying the protocol that would minimize the sum of such misallocation.

Thus, no court has ever tried to determine the award formula that would eliminate each particular type of marine-peril-related misallocation that might be generated, noticed that the formula that would eliminate one such type of misallocation would not eliminate the other types of marine-peril-related misallocation that could be generated, tried to determine the factors that would influence the amount of marine-peril-related misallocation of each relevant type that would be generated if the awards made deviated in either direction by various amounts from the awards that would eliminate that type of misallocation, attempted to determine the amount of misallocation of each relevant type that would be generated if a given set of awards were made (if a given award-calculation protocol were followed), or attempted to identify the set of awards (the awardcalculation protocol) that would minimize the sum of the marine-peril-related misallocation that was generated.

Second, no court has ever articulated the formula by which it calculates the award it makes in individual cases. Even if the courts had supplied the list of factors that the Kennedy treatise and other scholarly works claim influence judicial decisions and that list covered all the factors courts take into account when calculating marine-salvage awards, such a list would not constitute a formula-i.e., would not allow potential marine 
salvors and potential marine rescuees to predict the awards that will be made accurately. I can imagine circumstances in which it would be allocatively efficient for courts to provide less rather than more guidance about their future decisions to these parties-e.g., when the awards that are second-best-allocatively-efficient are higher than the awards that would minimize the misallocation that potential rescuees generate but lower than the awards that would minimize the misallocation that potential rescuers generate and the courts' concealment of their intentions leads potential rescuees to underestimate the awards that the court will make and potential rescuers to overestimate those awards. However, I suspect that the conditions for this result will rarely obtain. In general, even if (counterfactually) the courts were basing their marine-salvage awards on a formula that was second-best-allocatively-efficient, their failure to delineate the formula they were using would be allocatively inefficient.

Third, although the list of factors that allegedly influence the marine-salvage awards courts make contains many items that do relate to considerations that affect the award that would minimize particular types of marine-peril-related misallocation (e.g., the amount of marine-salvage-operation investment the salvor has made), the items in the list that do relate to such parameters do so only crudely. For example, although the salvor's classification (professional, semi-professional, casual) does relate to the fixed costs of salvageoperation investment the salvor's salving operating profits must cover, it is a far-from-accurate surrogate for such fixed-cost data.

Fourth, even when the list of factors contains some components of a figure that is relevant to the calculation of the second-best-allocatively-efficient award, it omits other components of the figure in question. Thus, although the list contains most components of the private variable cost of rescue-attempts, it omits the weighted-average-expected amount of variable costs a rescue-attempt will impose on the attempter by increasing the probability that cargo he is carrying will be lost or damaged. Similarly, although the list contains many components of the private and allocative benefits that a rescue-attempt should be expected to generate $e x$ ante, it omits the weighted-average-expected value of the lives that may be saved in pure-life-salvage situations.

Fifth, even when the list includes some relevant factor, in practice the courts may mismeasure the factor in question. Thus, the general view is that courts undervalue lives saved and at risk and injuries prevented or sustained.

Sixth, the list omits a number of determinants of the positive economic consequences of the awards given that an allocatively-efficient protocol would take into account. For example, the list does not include the number of rescue-attempts the successful salvor will make with the salvage-ship in question or the percentage of those attempts that will be successful (which one would have to know in addition to his fixed costs and the private variable cost of the successful rescue-attempt to determine the percentage by which the average award he receives when successful must exceed the average private variable cost of his successful rescue-attempts for him to earn a normal rate of return on his salvage-operation investments). 
Seventh, the list does not make reference to many determinants of the allocative efficiency of the positive economic consequences of the use of a particular award-protocol-e.g., the effect of successive investments in salvage-ship construction and equipment on (1) the allocative-efficiency gains that actual rescueattempts generate, once the relevant investments are made, and (2) the allocative-efficiency gains potential rescuees generate by rejecting avoidance-moves.

Eighth, as I have already indicated, the list seems not to reflect the possibility that the awards made may cause misallocation by inducing an allocatively-inefficient number of rescue-attempts to be made.

Ninth, the list clearly does not cover the allocative efficiency of the pre-incident avoidance-decisions of the rescuee, a factor that might well affect the award that is second-best or third-best allocatively efficient.

Tenth, although the list does cover the externalities a rescue-attempt would otherwise generate by interfering unnecessarily with other rescue-attempts made on the same body of salvage and various international conventions and privately-developed governance-structures have internalized to salvors much of the environmental consequences of their actions that admiralty law failed to internalize ${ }^{75}$ the list clearly does not make reference to most of the various Pareto imperfections that will individually and collectively distort the private value of the property and lives saved, the private fixed salvage-operation costs of the salvor, the private variable cost of rescue-attempts, and the private cost of potential-rescuee avoidance-moves.

Eleventh, although I assume that, unlike the list, the judges have indicated the direction in which their awards will be affected by variations in the parameters the list contains, the judges have not indicated the amounts by which the awards they announce will be affected by given variations in each such parameter, and (even if there is reason to believe that the courts have varied their awards in the right direction with changes in the parameters in question) there is no reason to believe that they have varied their awards to the right extent in response to changes in these parameters.

Of course, the preceding demonstration that neither the approach the courts took to identifying the protocol to use when calculating marine-salvage awards nor the protocol they chose to use for this purpose was second-best-allocatively-efficient does not establish the third-best-allocative-inefficiency of their conduct. It is conceivable that both the imperfectly-articulated approach the courts used to select a salvage-award protocol and the protocol they selected and used were third-best-allocatively-efficient-allocatively efficient, given the inevitable cost and probable inaccuracy of the various theoretical and empirical analyses that would be components of the second-best-allocatively-efficient approach and protocol. Indeed, I have already admitted that it would probably be third-best-allocatively-efficient to ignore some factors (some non-environmentaldamage-related Pareto imperfections) that a second-best-allocatively-efficient analyses would take into account. However, I see absolutely no reason to believe that the other features of the courts' approach and protocol that I have just pointed out would be deficiencies from the perspective of second-best-allocative-efficiency analysis 
would be strengths from the perspective of third-best-allocative-efficiency analysis. There is no reason to believe that muddling through is the third-best-allocatively-efficient approach to picking a salvage-award protocol, that the various deficiencies of the courts' list are individually unimportant or substantially cancel each other out, or that the cost of attempting to remedy these deficiencies would be prohibitive from the perspective of allocative efficiency, given the cost and inevitable imperfectness of any attempt at correction.

I began this Article by explaining why-even if the courts made third-best-allocatively-efficient marinesalvage awards-their efforts would not be as allocatively efficient as the most-allocatively-efficient set of marine-peril-related policies the State could adopt. This section has shown that the courts' performance in this area is almost certainly far more misallocative than it had to be.

7. A Critique Both of Landes and Posner's Conclusion That the "Judge-Made" Law of Marine Salvage Displays "Impressive Congruence With” Their General “Economic Efficiency of Judge-Made Law” Hypothesis and of the Type of Argument They Made to Support This Conclusion

As I indicated in the Introduction, ${ }^{76}$ in a classic article, William Landes and Richard Posner argue that what they refer to as “judge-made” marine-salvage law “is consistent with" and displays "impressive congruence with" their hypothesis that "the rules of judge-made law are best explained as efforts-however unwitting - to bring about [economically-] efficient results."77 Even if one ignores the differences between the claim that economic efficiency can predict the content of "judge-made" law and the claim that economic efficiency can explain "judge-made” law, ${ }^{78}$ it seems to me that Section 6 refutes Landes and Posner's conclusion, regardless of how generously (i.e., weakly) one interprets the critical expressions "is consistent with” and displays “impressive congruence with.”

However, as important as it is to refute the general “economic efficiency of 'judge-made' law” position to which Landes and Posner and many other Law \& Economics scholars subscribe, it is equally important to criticize the kind of argument that Landes and Posner and others use to support this position. The argument that

\footnotetext{
$76 \quad$ See the text preceding note 6 supra.

$77 \quad$ See Landes and Posner at 102.
}

78 The latter claim implies either that the economically-efficient resolution of that issue is the correct resolution of that issue as a matter of law or that, for some personal reason, judges are motivated to reach economically-efficient conclusions or that, for some institutional reason, judges are led to reach economically-efficient conclusions. Although I agree that the internal-to-law correct resolution of some legal issues is the most-economically-efficient resolution of those issues courts could devise, I do not think that this is true for all or even most legal issues. In part, this conclusion reflects my belief that the economically-efficient resolution of many moral-rights-related legal-rights issues is not the just resolution of those issues and, in part, my belief that much statutory law that is not designed to effectuate moral rights is also not allocatively efficient. (I should add that I also do not think that most just decisions are the most-economically-efficient decisions that were available to the relevant decisionmaker.) See Richard S. Markovits, op. cit. supra note 1. In addition, I do not think that judges believe either (1) that the economically-efficient resolution of all legal-rights issues is the just or internal-to-law correct resolution of those issues or (2) that they will best be able to further their judicial or nonjudicial careers by making economically-efficient decisions. Landes and Posner's inclusion of the expression "however unwitting" suggests that they do not disagree with this last point. Finally, although I agree that there may be some tendency for litigants who would benefit from the economically-efficient resolution of legal-rights issues to spend more money arguing for such an outcome than litigants who would benefit from the economically-inefficient resolution of that issue would spend arguing for their preferred resolution of the issue in question (since the former litigants have more equivalent-dollars to gain than the latter have to lose from the adoption of an economically-efficient decision standard), I doubt that any such difference is a sufficiently important determinant of the content of "judge-made" law for that content to be "explicable" in this way. For an explanation of why I have enquoted "judgemade," see note 11 supra. 
Landes and Posner use to justify their conclusion that "judge-made” marine-salvage law is allocatively efficient has much in common with the kind of storytelling through which they and other scholars who believe in the allocative efficiency of “judge-made” law in general try to establish the allocative efficiency of legal doctrines and their application in general. I will close this section and article by describing and criticizing the type of argument that Landes and Posner make in their marine-salvage piece and explaining its relationship to the general class of arguments that they and others use to establish the allocative efficiency of other "judge-made" doctrines and their application.

Basically, Landes and Posner proceed by (1) listing the factors that the courts have taken into consideration when making marine-salvage awards, (2) explaining that those factors do affect the award that would be allocatively efficient in a given case or would play a role in the most-allocatively-efficient formula that courts would use to calculate marine-salvage awards because they affect the impact that the award(s) would have on the allocative efficiency of particular types of private decisions they would affect, (3) arguing that the courts vary the awards they make in the allocatively-efficient direction in response to variations in the magnitude of the factors they consider, and (4) offering arguments for the allocative efficiency of courts' ignoring certain factors that would otherwise have been allocatively efficient for them to take into account. ${ }^{79}$

The implausibility of many of these latter arguments aside, this type of argument has the following deficiencies:

(1) its analysis of the allocative-efficiency relevance of the factors the courts consider is undercut by its failure to take account of the full range of choices whose substance and allocative efficiency both the factors in question and marine-salvage awards affect;

(2) its analysis of the impact of the factors the courts consider on the substance and allocative efficiency of the choices it recognizes those factors affect is undercut by its failure to recognize the interdependence of many of the choices in question;

(3) its analysis of the impact of marine-salvage awards on the allocative efficiency of the choices it recognizes those awards will affect (and hence its analysis of the allocative efficiency of particular marine-salvage awards or of particular formulae for calculating such awards) is undermined by its failure to take account of the fact that the courts have ignored many of the determinants of the award that would be most-allocatively-efficient for them to make-inter alia, the full range of Pareto imperfections that individually and in combination distort the profitability of the choices the awards affect and/or cause individual choosers to make choices that are not in their individual interest;

(4) its analysis of the allocative-efficiency-relevance of particular factors is undermined by its failure to take account of the fact that awards that eliminate (or reduce) the misallocation generated by one or more types of decisions may increase the misallocation generated by one or more other types of decisions;

Thus, Landes and Posner argue that the American courts' practice of counting the value of lives saved when property as well as lives have been rescued but not providing compensation for "pure life” salvors may be allocatively efficient because-although allocative efficiency will be furthered by giving potential rescuers appropriate incentives to save lives as well as property when both are imperiled_-altruism may secure allocative efficiency when only lives are in danger. See Landes and Posner at 104-05 and n. 48. 
(5) its analysis of the allocative efficiency of judicially-prescribed salvage-awards is limited by its failure to consider whether the courts have made the awards they issue vary to the allocativelyefficient extent in response to given changes in the value of the factors they consider (by its focusing exclusively on whether the courts vary the awards they make in response to changes in the value of relevant parameters in the allocatively-efficient direction); and

(6) for some purposes, the type of conclusion that this type of argument can generate does not provide the information that is required - even if the courts made the awards that were the mostallocatively-efficient awards they could prescribe, standing alone such awards would not constitute the most-allocatively-efficient response the State could make to the possibility of marine peril.

I should add that Landes and Posner (and others who make the kind of argument they make in the article this piece criticizes) never acknowledge the possibility much less the reality that the most-allocatively-efficient response that courts can make to some problem does not by itself constitute the most-allocatively-response the State can make to that problem.

Admittedly, some of the deficiencies of the argument I just criticized will not appear when the judicial decisions under scrutiny are binary rather than continuous-e.g., when the issue is (1) is a particular defendant strictly liable or liable only for the consequences of his negligence or (2) was a particular defendant's conduct negligent as opposed to (3) how large an award (how much damages) should a particular defendant have to pay? However, other deficiencies of the Landes-Posner marine-salvage-award argument are equally salient when the judicial decisions whose supposed allocative efficiency is being established are binary. For example, in a previous article, ${ }^{80}$ I showed that Landes and Posner's argument for the allocative efficiency of the (alleged) common-law practice of holding members of an industry strictly liable during the industry's infancy but liable only if found negligent when the industry has matured was flawed inter alia by its failure to consider the full range of allocatively-inefficient decisions that businesses could make that would not in practice be assessed for negligence and the large number of Pareto imperfections other than accident-or-pollution-loss externalities not internalized by legal-liability rules that could distort the profitability of the choices in question (and whose magnitude would, in different cases, increase and decrease as the industry in question matured). Somewhat less complicatedly but equally tellingly, Bob Rabin pointed out ${ }^{81}$ that Posner's conclusion that a trolley company had not behaved negligently in a case in which a plaintiff was electrocuted when a long wire he was carrying came into contact with uninsulated overhead trolley wires beneath an overpass was critically affected by Posner's failure to consider the possible negligence of the railroad's failure to post warnings on both sides of all

80 Richard S. Markovits, The Allocative Efficiency of Shifting From a "Negligence" System to a "Strict-Liability" Regime in Our Highly-Pareto-Imperfect Economy: A Partial and Preliminary Third-Best-Allocative-Efficiency Analysis, 73 CHI.-KENT L. REV. 11, 123-32 (1998).

81 Robert L. Rabin, The Historical Development of the Fault Principle: A Reinterpretation, 15 GA. L. REv. 925, 955 (1981), discussing Landes and Posner's treatment of Adams v. Bullock, 227 N.Y. 208, 125 N.E. 93 (1919) in William A. Landes and Richard M. Posner, The Positive Economic Theory of Tort Law, 15 GA. L. Rev. 851, 894 (1981). Posner's argument was that—given the low probability of this kind of loss and the high cost of placing underground the wire that caused it (which had to be uninsulated to supply electricity to the trolley) - the trolley company's decision to use overhead wires was not negligent (because the cost of placing the wires underground was higher than the reduction in weighted-average-expected accident losses placing them there would generate). 
such overpasses-i.e., the failure to consider the possibility that even if the trolley company's decision to place their necessarily-uninsulated wires overhead rather than in the ground was not negligent, their failure to post warnings may have been negligent.

In my judgment, the common law is not in general allocative efficient and should not in general be allocatively efficient. Law \& Economics scholars, who at least supposedly are expert in executing allocativeefficiency analyses, ${ }^{82}$ think otherwise in part because like almost everyone (including me) they would like their expertise to have more value rather than less (e.g., to put them in a position to determine the internally-correct answer to legal-rights question). Despite their inability to explain why judges should make choices that are allocatively efficient, ${ }^{83}$ many Law \& Economics scholars continue to insist that what they term "judge-made law” is allocatively efficient and to back up this conclusion with bad arguments that have many or all of the deficiencies of the argument that Landes and Posner make for the allocative efficiency of marine-salvage-award law. I chose to close this article with this more general critique (1) because the efforts of these Law \& Economics scholars have an impact on the perceptions of other legal scholars and on legal pedagogy and (2) because the problematic character of this work has implications both for the role that economists should play in the policy-making process and for decisions that university administrations should make on interdisciplinary appointments and programs involving economics.

\section{CONCLUSION}

\section{This Article}

(1) delineates the different kinds of allocative costs that marine-peril contingencies can generate and the different kinds of marine-peril-related decisions that can generate allocative inefficiency (marine-salvage-operation investment decisions; decisions about whether to offer to attempt or to actually attempt marine rescues; decisions about the character of the marine-rescue attempts that are made; decisions by potential rescuees to accept or reject offers of marine-rescue attempts; and decisions by potential rescuees to make or reject various marine-peril-avoidance moves);

(2) defines the formal meaning of "the most-allocatively-efficient response a State can make to marine-peril contingencies”;

(3) explains why, standing alone, judge-prescribed marine-rescuee-to-rescuer-compensation awards cannot minimize the allocative cost that marine peril generates (the misallocation that marineperil-related decisions generate);

(4) discusses the interdependence of the various types of marine-peril-related decisions that can be made;

\footnotetext{
82 The word "supposedly" reflects my belief that the economic-efficiency analyses that most Law \& Economics scholars execute are vitiated (1) by their failure to consider the impact that the policies they are analyzing have on many of the types of resource misallocation those policies will affect and (2) by their failure to respond appropriately to The General Theory of Second Best. For a general critique of Law \& Economics scholarship, see Richard S. Markovits, Truth or Economics: On the Definition, Prediction, and Relevance of Economic Efficiency (unpublished book manuscript under submission, 2005).

$83 \quad$ Note the "however unwitting" language in the Landes and Posner statement quoted in the text at note 6. For a critique of the various arguments economists make to explain why judges should be expected to make allocatively-efficient decisions, see Richard S. Markovits, Legal Analysis and the Economic Analysis of Allocative Efficiency, 8 HofSTRA L. REV. 811, 848-72 (1980).
} 
(5) defines the second-best-allocatively-efficient and the third-best-allocatively-efficient approach to deciding particular issues and the second-best-allocatively-efficient and third-best-allocativelyefficient resolution of a particular issue;

(6) executes a partial and preliminary second-best analysis of the factors that determine the impact of any marine-salvage-award formula both on each of the types of marine-peril-related misallocation such awards can affect and on the total amount of marine-peril-related misallocation that the use of any given marine-salvage-award formula will generate;

(7) speculates on the differences between the marine-salvor-compensation formula that is secondbest-allocatively-efficient and the formula that is third-best-allocatively-efficient;

(8) provides an account of the protocol the courts allegedly use to determine the compensation they order defendant marine rescuees to pay plaintiff marine rescuers who have not been able to negotiate a binding price for their services ;

(9) analyzes the second-best and third-best allocative efficiency of that protocol—i.e., delineates the respects in which that protocol is definitely not second-best-allocatively-efficient and explains why it is extraordinarily unlikely to be third-best-allocatively-efficient;

(10) points out that the preceding analysis refutes Landes and Posner's claim that the law of marine salvage "is consistent with" and displays "impressive congruence with" their hypothesis that "the rules of judge-made law are best explained as efforts-however unwitting — to bring about [economically-]efficient results;”;4

(11) delineates the structural deficiencies of the type of argument with which Landes and Posner attempt to establish their conclusion that marine-salvage law is allocatively efficient;

(12) asserts that Law \& Economics scholars who believe that "judge-made" law in general is allocatively efficient almost always attempt to justify this conclusion with the same type of argument that Landes and Posner made about marine-salvage law; and

(13) explains why it is important not only to refute the conclusion that "judge-made law" is allocatively efficient but to demonstrate the inadequacy of the type of argument with which scholars who believe that "judge-made law" is allocative efficient attempt to bolster this position. 


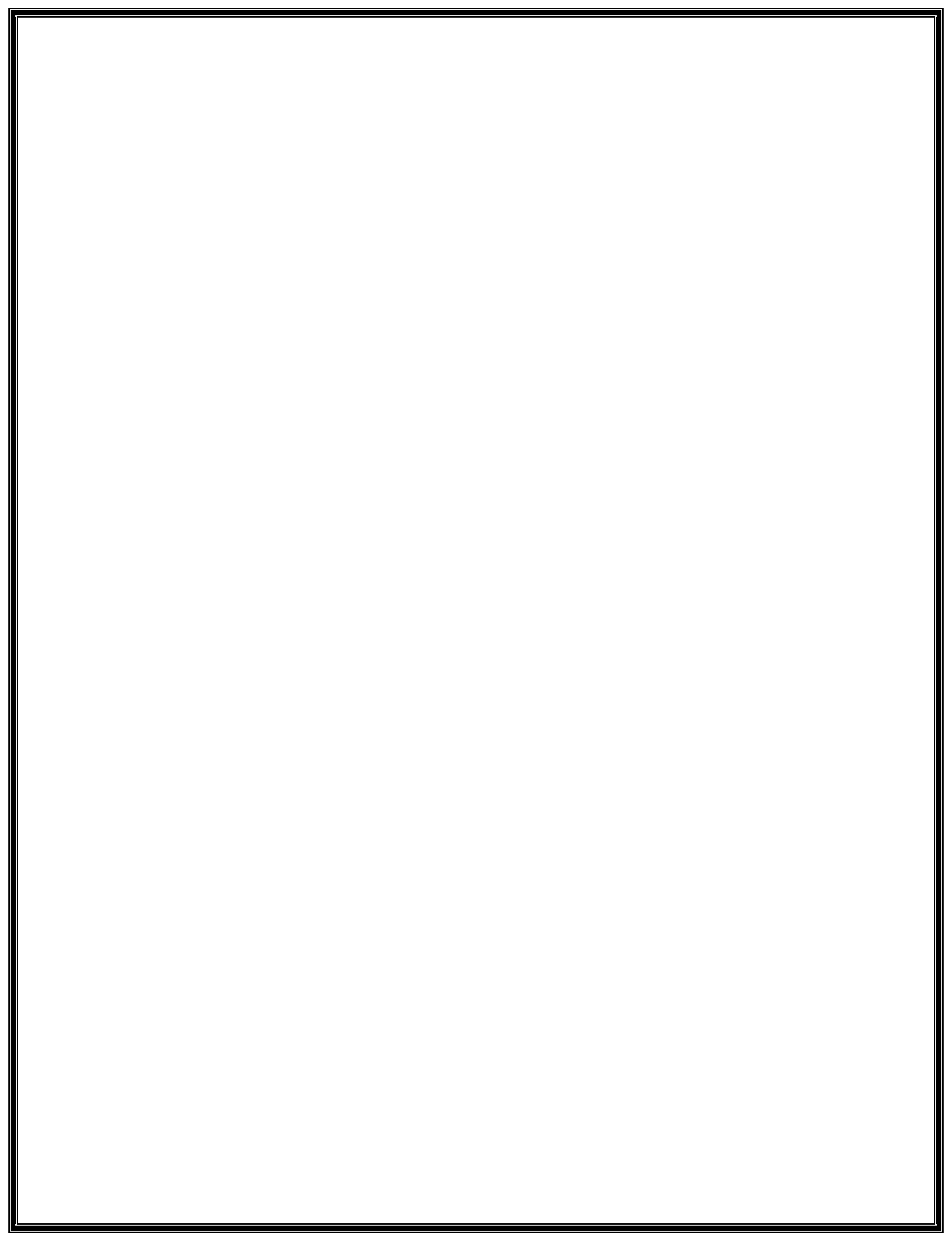

